Technological University Dublin ARROW@TU Dublin

\title{
Emerging Food Processing Technologies and Factors Impacting their Industrial Adoption
}

Anushree Priyadarshini

Technological University Dublin, anushree.priyadarshini@tudublin.ie

Gaurav Rajauria

$U C D$, gaurav.rajauria@ucd.ie

Colm. P. O'Donnell

$U C D$, colm.odonnell@ucd.ie

See next page for additional authors

Follow this and additional works at: https://arrow.tudublin.ie/buschacart

Part of the Accounting Commons

\section{Recommended Citation}

Gaurav Rajauria, G. et al. (2019) Emerging food processing technologies and factors impacting their industrial adoption, Critical Reviews in Food Science and Nutrition, 59:19, 3082-3101. doi:10.1080/ 10408398.2018.1483890

This Article is brought to you for free and open access by the School of Accounting and Finance at ARROW@TU Dublin. It has been accepted for inclusion in Articles by an authorized administrator of ARROW@TU Dublin. For more information, please contact arrow.admin@tudublin.ie, aisling.coyne@tudublin.ie, gerard.connolly@tudublin.ie.

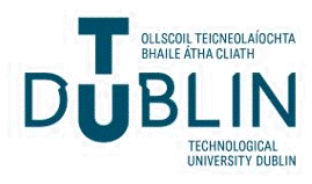


Authors

Anushree Priyadarshini, Gaurav Rajauria, Colm. P. O'Donnell, and Brijesh K. Tiwari

This article is available at ARROW@TU Dublin: https://arrow.tudublin.ie/buschacart/32 
Emerging Food Processing Technologies and Factors Impacting their Industrial Adoption

Anushree Priyadarshini ${ }^{1}$, Gaurav Rajauria ${ }^{2 *}$, Colm P. O’Donnell ${ }^{3}$, Brijesh K. Tiwari ${ }^{4}$

${ }^{1}$ College of Business, Dublin Institute of Technology, Aungier Street, Dublin 2, Ireland [Email: anushree.priyadarshini@dit.ie]

${ }^{2}$ School of Agriculture and Food Science, University College Dublin, Lyons Research Farm, Celbridge, Co. Kildare, Ireland [Email: gaurav.rajauria@ucd.ie]

${ }^{3}$ School of Biosystems and Food Engineering, University College Dublin, Belfield, Dublin 4, Ireland [Email: colm.odonnell@ucd.ie]

${ }^{4}$ Department of Food Biosciences, Teagasc Food Research Centre, Ashtown, Dublin 15, Ireland [Email: brijesh.tiwari@teagasc.ie]

\section{Corresponding author*}

Ph: +353 (0) 16012167

Email: gaurav.rajauria@ucd.ie 


\section{Abstract}

2 Innovative food processing technologies have been widely investigated in food processing 3 research in recent years. These technologies offer key advantages for advancing the 4 preservation and quality of conventional foods, for combatting the growing challenges posed 5 by globalization, increased competitive pressures and diverse consumer demands. However, 6 there is a need to increase the level of adoption of novel technologies to ensure the potential 7 benefits of these technologies are exploited more by the food industry. This review outlines 8 emerging thermal and non-thermal food processing technologies with regard to their 9 mechanisms, applications and commercial aspects. The level of adoption of novel food 10 processing technologies by the food industry is outlined and the factors that impact their 11 industrial adoption are discussed. At an industry level, the technological capabilities of 12 individual companies, their size, market share as well as their absorptive capacity impact 13 adoption of a novel technology. Characteristics of the technology itself such as costs involved 14 in its development and commercialization, associated risks and relative advantage, its level of 15 complexity and compatibility influence the technology's adoption. The review concludes that 16 a deep understanding of the development and application of a technology along with the factors 17 influencing its acceptance are critical for its commercial adoption.

18 Keywords: consumer acceptance; thermal technology; non-thermal technology; food 19 preservation; industrial adoption; technology diffusion 


\section{INTRODUCTION}

22 The food industry is an increasingly competitive and dynamic domain, with increasing 23 consumers' cognizance about what they consume. Nowadays consumers demand that food 24 products must provide among other things, convenience, diversity, sufficient shelf life and low caloric content, low cost and environmental credentials. Important characteristics defining food quality such as appearance, texture, taste and nutritional content are strongly impacted by the way foods are processed. In order to meet these consumer demands the processing of food is becoming increasingly challenging and diverse, including alterations to prevailing food processing techniques and adoption of new innovative processing technologies (Ma and McSweeney 2008, Capitanio, Coppola, and Pascucci 2010).

A range of new food processing technologies have been investigated and developed to modify or replace traditional food processing techniques so that better quality and more consumer preference oriented foods can be manufactured (Knoerzer et al. 2011). Much attention has been

34 focused on enhancing the process efficiency, productivity, quality, safety and stability of food products in a healthier way. The demand of more resilient and sustainable food options is further complicated by the increasing global population. Prevalence of various food related disease outbreaks, consumer awareness, safety, shelf life, quality and nutritional properties of foods are now becoming the primary concern of the food industry. However, the acceptance of new food products generally depends on the possible benefits and risks associated with the

40 foods and the processing technology adopted. Though, food processing is an ancient 41 phenomenon, its focus from home cooking to more industrial processing has increased the emphasis on safety and nutritional quality of product (Van Boekel et al. 2010).

43 The nutritional quality of food is dependent on a range of factors from farm to fork including 44 the quality of raw material, processing techniques, packaging, transportation, storage and 
finally cooking (Moskowitz, Beckley, and Resurreccion 2012, Falguera, Aliguer, and Falguera

2012). Fresh raw produce is transformed into a value added food products by passing through a series of unit operations. Raw materials are first processed by techniques such as washing, cleaning, drying, chilling, freezing, sorting, grading, milling storage, and homogenization. These pre-processed materials are then transformed into value added foods and ingredients by a range of conventional or novel thermal and non-thermal techniques (Boye and Arcand 2013).

In last few decades, a range of novel processing techniques have been developed to improve physico-chemical properties of foods by minimizing processing (e.g. thermal degradation) impacts. The primary focus of these innovations was to increase production and process efficiency with minimal or no changes in nutritional properties of foods, reduce energy consumption and reduce food wastage by improving shelf life. Several novel thermal and nonthermal, process technologies have been developed to help ensure product safety, quality and acceptability. However, the development of these novel technologies is of little use until their potential is exploited by their use in industrial manufacturing processes (Sun 2014). To date the adoption of available technologies by the food industry was largely determined by the need for growth, increase in revenue and productivity, while the primary factors restricting adoption of these technologies has been availability of resources, familiarity of technology usage and market risks. Now given the challenges posed by globalization and diverse consumer demands for a technology to be adopted by industry, it must be internationally competitive, produce high quality products, meet environmental standards and regulations, as well as meet consumer preferences (Chen, Anders, and An 2013).

66 European studies have investigated the acceptance of novel technologies and suggest that due

67 to differences in opinions on the 'benefits' of the technologies, consumers do not always prefer 68 new technologies with demonstrated clear health benefits (Siegrist 2008, Frewer et al. 2011).

69 Others have argued that consumer acceptance mainly relies on the perceived benefits 
associated with the products (Olsen, Grunert, and Sonne 2010, Henchion et al. 2013, Verneau

et al. 2014). Interestingly, though consumer attitudes and perceptions have been investigated, limited research has focused on other factors impacting industrial adoption of new technologies (Chen, Anders, and An 2013, Frewer et al. 2011, Rollin, Kennedy, and Wills 2011). As new technologies are increasingly being developed to improve production processes and to yield better quality products, understanding the development and application of these innovative technologies is vital. Exploring the various factors impacting their industrial adoption, such as food laws that are recognized by strong influence and interference, market and environmental factors are also key to exploiting the technological and commercial potential of these innovative technologies.

\section{NOVEL THERMAL TECHNOLOGIES}

\subsection{Radio Frequency Heating}

Radio frequency $(\mathrm{RF})$ heating or dielectric heating is a thermal process wherein a RF generator creates a high-frequency radio wave or alternating electric field to heat a dielectric material. This endogenous (volumetric) heating is a characteristic feature of RF technology wherein heat is generated instantaneously, selectively, uniformly and accurately at the centre of the food product, regardless of its thermal conductivity, density or size (Maloney and Harrison 2016).

Dielectric energy induces molecular friction in water molecules to produce heat, therefore RF heating is influenced in part by the moisture content of the food. It is evident that every food product has certain dielectric properties and these properties are dependent on viscosity, water content, chemical composition, temperature and other physiochemical properties of the food (Alfaifi et al. 2013, Uyar et al. 2015). RF is a promising technology with numerous applications in the food industry which can be applied for continuous and batch heat processes. However

93 its usage for continuous pasteurization and sterilization of food products has not been fully 
94 investigated (Huang, Marra, and Wang 2016, Hussein, Yetenayet, and Hosahalli 2014).

95 Compared to conventional thermal processing, RF requires less energy and penetrates deeply, rapidly and uniformly even in large size food particles (Zheng et al. 2016, Maloney and

97 Harrison 2016, Jiao, Tang, and Wang 2014).

Commercially, RF heating is suitable for use in many processing applications in the food industry (Table 1). The first and most widely reported applications of RF technology in the

100 food industry are post-baking drying of biscuits, crackers and breakfast cereals. According to

101 STALAM, an Italian RF equipment manufacturer, a full baking process (without convention heating) using electromagnetic waves can be achieved by distributing the appropriate amount of energy on to a dough matrix (Awuah, Ramaswamy, and Tang 2014). Whereas, ThermexThermatron, a USA based RF unit manufacturer recently introduced a conveyor based RF drying system (Fig. 1) with sustained power output levels of up to $120 \mathrm{~kW}$ which can provide the desired heat and heating rate using a PLC systems for real time response (Nagaraj et al. 2015). The technology is suitable for quick defrosting of frozen fish, meat and other raw or processed food products (Alfaifi et al. 2013, Awuah, Ramaswamy, and Tang 2014, Ha et al. 2013). Furthermore, baking of bread, thawing of food products, disinfestation and sanitization

110 of dry food commodities such as grains, seeds, legumes and dry fruits, and sterilization of 111 packaged solid or viscous liquid food products may also be carried out using RF heating (Jiao,

112 Tang, and Wang 2014, Huang, Marra, and Wang 2016, Uyar et al. 2015, Zhou and Wang 2016,

113 Mishra and Sharma 2016). Consumer concerns over product quality and increasing production

114 costs have motivated industry to adopt novel drying technologies such as radio frequency.

115 However as start-up costs are high and the technologies are relatively complicated as compared

116 to conventional drying techniques, their current applications are mainly limited to small

117 categories of fruits and vegetables only (Zhang et al. 2006). Strayfield (UK), STALAM (Italy), 
PSC (USA), Thermex-Thermatron (USA) and Radio-Frequency Company (USA) are suppliers

119 of RF heaters for commercial applications worldwide (Awuah, Ramaswamy, and Tang 2014).

\section{$120 \quad 2.2 \quad$ Microwave Heating}

121 Microwave heating is a thermal process involving microwave electromagnetic radiations (1$100 \mathrm{GHz}$ ) or high-frequency alternating electric field and heat transfer. The rapidly varying electric and magnetic fields generate heat, and any food material that is exposed to these radiations is heated up. In microwave heating, electromagnetic waves oscillate within the oven at the most effective frequency range for dielectric heating which lies between 0.915 and 2.45 GHz. (Leonelli and Mason 2010). The absorption of microwave energy is dependent on the dielectric and magnetic properties of the treated material. In the context of microwave heating, the electrical properties of materials are known as dielectric properties, and these properties influence how food materials interact with electromagnetic energy. When liquid foods are treated with microwave as the presence of water in liquid foodstuffs enables them to absorb electromagnetic energy very rapidly. Slight changes in dielectric properties influence the microwave conditions of food products considerably (Ahmed and Ramaswamy 2004). Microwave intensity weakens as microwaves travel into the food product, the outer food

134 surface absorbs more energy and heats up faster than the inner region. This results in uneven 135 heating in deeper regions along with nutrient loss due to high surface temperature (Maloney and Harrison 2016, Leonelli and Mason 2010, Roselló-Soto et al. 2016).

137 The application of microwave in domestic and industrial food processing is rapidly increasing.

138 The food industry has adopted the technique because of its rapid and uniform energy transfer, 139 selective and volumetric heating, easily controllable and clean environment at the point of use 140 (Maloney and Harrison 2016, Tang 2015, Leonelli and Mason 2010, Chen et al. 2016). The 141 food industry is developing more and more products especially well-suited to microwave 142 heating. Microwave heating may be efficiently used in both domestic and industrial operations 
143 for drying of foods, baking of biscuits and breads, precooking and cooking of meals, cereals,

144 meats and meat products, thawing of frozen food products, blanching of vegetables,

145 pasteurization and sterilization of fast food, meals and various other food products (Leonelli

146 and Mason 2010, Liu and Lanier 2016, Monteiro, Carciofi, and Laurindo 2016, Roselló-Soto

147 et al. 2016, Ozkoc, Sumnu, and Sahin 2014, Valero, Cejudo, and García-Gimeno 2014,

148 Shaheen et al. 2012, Lee, Choi, and Jun 2016). Because of the minimum come-up time (CUT)

149 to reach the desired process temperature, microwave heating is preferred for high-temperature

150 short-time (HTST) processing for liquid and packed food products. Microwave heating

151 pasteurization and sterilization not only minimizes bacterial growth but also reduces the

152 degradation of desired components in the food (Leonelli and Mason 2010, Shaheen et al.

153 2012). During baking applications, it helps to retain the distinctive flavor, color and texture and

154 minimizes the cracking of the baked products (Chen et al. 2016, Valero, Cejudo, and García-

155 Gimeno 2014). Microwave heating has been successfully combined in batch and continuous

156 forms with RF heating to obtain the benefits of both dielectric and conduction forms of heating

157 (Leonelli and Mason 2010, Valero, Cejudo, and García-Gimeno 2014, FDA 2015b). This

158 technology has an advantage over conventional microwave heating because it utilizes longer

159 wavelengths than microwave which can penetrate deeper into the food product without surface

160 overheating or hot or colds spots (Shaheen et al. 2012). Though, the whole process needs an

161 optimization prior to its application especially in the case of a composite food material, or a

162 biphasic food system (Chen et al. 2016).

163 The microwave manufacturers are able to customize equipment to specific applications and 164 food product types, and the technology is successfully utilized by food manufacturers across

165 Asia, Europe and the USA (Maloney and Harrison 2016, Valero, Cejudo, and García-Gimeno

166 2014). However, the industrial adoption of microwave heating has been limited by its high

167 initial capital cost. Microwave technology offers low energy efficiency compared to 
conventional drying techniques (Chua and Chou 2014). Fig. 2 shows a typical conveyor modular industrial microwave systems built by Thermex Thermatron (USA). The unit can apply up to $100 \mathrm{~kW}$ of power to the product being heated and can be operated at $915 \mathrm{MHz}$

171 (Goullieux and Pain 2014). Though several type of commercial microwave instruments are 172 currently in use in Europe (Belgium, Holland, and Italy), Japan and USA for multiple food 173 sterilization applications, none of them are designed for high power (> $125 \mathrm{~kW})$ operations 174 (Leonelli and Mason 2010). In order for the microwave drying technique to be economically viable and adopted more widely by industry, energy conservation features must be incorporated (Chua and Chou 2014) and studies carried out to demonstrate its viability for large scale 177 commercial adoption.

\subsection{Ohmic Heating}

179 Ohmic heating $(\mathrm{OH})$, also referred as Joule heating, electro-heating or electro-conductive 180 heating, is an advanced thermal processing method wherein electric current is passed through 181 a food, which produces heat due to the electrical resistance of the food materials (Varghese et al. 2014, Wongsa-Ngasri and Sastry 2016). Ohmic treatment has no penetration depth limitation compared to microwave and radio frequency heating. However, the electrodes in

184 ohmic heating should be in contact with the food containing liquid large enough to modulate energy. In contrast to conventional thermal processing, $\mathrm{OH}$ uniformly heats the entire mass of the product resulting in high quality product with almost no deterioration of its nutrients

187 (Wongsa-Ngasri and Sastry 2016, Deeth and Datta 2011). OH helps to conserve almost all the nutrients by avoiding local overheating of food products (Wongsa-Ngasri and Sastry 2016).

189 The technique also enables large particulates foods (up to $2.54 \mathrm{~cm}$ ) to heat at similar rates, thus 190 allowing it to be used as high temperature short time (HTST) and ultra-high temperature (UHT) 191 technique on solids or suspended materials which cannot be achieved by conventional heat 192 processing technologies (Deeth and Datta 2011, Kaur and Singh 2015, Darvishi et al. 2015, 
193 James and James 2014). Thus, heating liquid foods containing large particulates, such as soups,

194 stews, and fruit slices in syrups and sauces, and heat sensitive liquids are considered to be the 195 most promising applications of $\mathrm{OH}$ in the food industry (Wongsa-Ngasri and Sastry 2016, Kaur 196 and Singh 2015, Saxena, Makroo, and Srivastava 2016, Cho, Yi, and Chung 2016).

$197 \mathrm{OH}$ is an emerging technology that provides the food industry with an opportunity to produce 198 high quality, value-added, shelf-stable products along with large number of unexplored future 199 applications. Other potential possibilities for $\mathrm{OH}$ include extraction, fermentation, thawing, sterilization, pasteurization, dehydration, blanching, peeling, evaporation, packaging, starch gelatinization detection and heating of foods to serving temperature (Table 1) (Varghese et al. 202 2014, Duygu and Ümit 2015, Fowler and Park 2015, Loypimai et al. 2015, Ito, Fukuoka, and 203 Hamada-Sato 2014, Yildiz-Turp et al. 2013, Bastías et al. 2015, Ramaswamy et al. 2014). 204 Additional to heating, recent research data strongly suggests that $\mathrm{OH}$ may present thermal and mild non-thermal cellular damage and cause microbial inactivation in food products. However, more knowledge regarding combined effect of temperature and electric field on the destruction

207 kinetics of microorganisms is needed (Varghese et al. 2014, Duygu and Ümit 2015, Pan, 208 Atungulu, and Li 2014).

209 The technology is economic, environmental friendly and is currently employed for commercial 210 applications. The technology can easily be integrated into both new and existing equipment and processing systems (Varghese et al. 2014, Deeth and Datta 2011). SPX (formerly APV

212 Ltd.) was the first company in the UK to sell commercial $\mathrm{OH}$ systems for fruit product 213 processing. Emmepiemme, an Italian company, manufactures most of $\mathrm{OH}$ systems in Europe 214 for fruits and vegetables processing (Pan, Venkitasamy, and Li 2016). Over twenty commercial 215 systems are currently in use across Europe, Japan, and the United States supplied by UK, USA 216 and Italian manufacturers. The widespread commercial adoption of $\mathrm{OH}$ in the United States 217 was enabled by FDA regulatory approval (Bengtson et al. 2006). Although the economics and 
218 technology appear favorable, more research is needed to completely understand the impact of

219 specific $\mathrm{OH}$ instrument designs and methods for confirming temperatures within individual

220 solids (Varghese et al. 2014).

221

222

223

224

225

226

227

228

229

230

231

232

233

234

235

236

237

238

239

240

241

242

\subsection{Infra-Red Heating}

Infrared is a kind of electromagnetic radiation that lies between ultraviolet and microwave energy region. Based upon its spectral range, infrared radiations are normally categorized into near-infrared (700-1400 nm), mid-infrared (1400-3000 nm), and far-infrared (3000-10000 nm) regions (Maloney and Harrison 2016, Rastogi 2015). Far-infrared is the most suitable for food processing because most food constituents absorb radiation in the far-infrared region (Rastogi 2012, Wang et al. 2014). Infrared (or radiant) heating is an indirect mode of heating wherein electromagnetic energy penetrates the food, gets adsorbed on the surface and then converts to heat. The heat adsorbed on the food surface is mostly by radiation but to a lesser extent by convection and conduction mechanism. The magnitude of heating by radiant energy depends upon the food surface characteristics as well as food color, therefore, IR radiation is typically used to alter the food quality by modifying the flavor, aroma and surface color of the food products. IR rapidly and uniformly heats the product which not only reduces the processing time and energy costs but also prevents the product overheating because of rapid heating rates. The temperature of the air inside the instrument can be kept constant because the air is not heated by IR which helps to controls the product overheating during processing (Wang et al. 2014, Mao et al. 2011, Maloney and Harrison 2016).

Due to its compact design with high controllability and safety, IR heating has been widely adopted in the food industry for cooking, frying, drying, dehydration, roasting, baking, peeling, blanching, and pasteurization of agricultural and food products (Rastogi 2012, Moreirinha et al. 2016, Ramaswamy, Krishnamurthy, and Jun 2012). Recently, IR heating has been successfully employed to inactivate lipooxygenase, lipases, $\alpha$ amylases and other enzymes 
243 responsible for the development of off-flavors and deterioration of fruits and vegetables (Table

244 1). Additionally, it is effective to inactivate bacteria, spores, yeast, and mold in both liquid and

245 solid foods (Huang et al. 2014, Bermúdez-Aguirre and Barbosa-Cánovas 2011).

246 The potential of this technology has only been exploited to a limited extent for heating purposes

247 in the food industry. The technology can penetrate and supply heat to only a few millimeters

248 below the surface of a sample which limits its application for heating a small number of food

249 product (Rastogi 2015, Rastogi 2012). Additionally, this poor penetration capacity of IR slows

250 down the temperature increase of solid foods as their thermal conductivity (k) is much lower

251 than the liquid foods. To make the penetrative radiation energy more effective, IR heating may

252 be used in combination with other conventional modes of heating for applications such as

253 freeze drying, dehydration, cooking and baking (Wang et al. 2014, Mao et al. 2011).

254 3. NON-THERMAL TECHNOLOGIES

\subsection{High Pressure Processing}

256 High pressure processing (HPP), also termed as high hydrostatic pressure and ultra-high

257 pressure, is a food processing method which is increasingly being exploited by the food 258 industry since the first commercial HPP processed product was produced in 1990. The technology was initially invented in Japan and is now commercially implemented and accepted worldwide (Pingen et al. 2016, Tsevdou, Eleftheriou, and Taoukis 2013). The technology is

261 basically a cold pasteurization method that has been employed for pathogen inactivation or

262 reduction, protein denaturation, shelf life extension and preservation of all type of solid and 263 liquid food products (Table 1) (Tribst et al. 2016, Zhou, Karwe, and Matthews 2016). The HPP works on isostatic and Le Chatelier's principle. The effect of HP on physical properties of food is governed by isostatic principle while food chemistry and microbiology is administered by

266 Le Chatelier's principle. In HPP, the food is treated under ultra-high pressure which is 
instantaneously and uniformly transmitted throughout the food product regardless of the size or shape of the food. This high pressure stimulates the phase transition or changes the molecular configuration that are associated with a decrease in volume, but oppose reaction involving volume increase (Le Chatelier's principle) (Norton and Sun, 2008). Due to this fact, the chemical properties (especially covalent bond) of molecules are intact whereas the tertiary and quaternary structures (mainly maintained by hydrophobic and ionic interactions) of molecules are transformed by high pressure. Thus, the process inactivates microbial and enzymatic activities of food without exposing it to high heat or drying treatments, and hence facilitates retention of quality parameters (Tribst et al. 2016). HPP is safe, less time consuming, energyefficient and waste free technology and works at room temperature. Furthermore, the technique does not depend on the size, shape or composition of products and meets the highest hygienic requirements, as the product can be treated post packaging and the overall processing cost (inclusive investment and operation costs) has been estimated to 10-15 Euro cent per $\mathrm{kg}$ of product (Tsevdou, Eleftheriou, and Taoukis 2013). In contrast to conventional processing methods, HPP retains the taste and freshness of the product to a higher level and does not result in cooking loss, thus resulting in a high product yield (Tsevdou, Eleftheriou, and Taoukis 2013).

High-pressure thermal sterilization (HPTS), wherein high pressure is applied at high temperatures as a tool for sterilization, has been used to improve food safety and food quality. The technique works on the synergistic effects of high temperatures (90 to $121^{\circ} \mathrm{C}$ ) and high pressures (above or equal to $600 \mathrm{MPa}$ ) for a shorter time period which accelerates the inactivation of microbial endospores in low-acid media. Though the technology has been used

289 for canned food products, it is not yet available at industrial scale (Sevenich et al. 2014,

290 Barbosa-Cánovas and Juliano 2008). According to Sevenich et al. (2014), the absence of an indicator strain to demonstrate an acceptable inactivation of pathogenic and spoilage bacterial 
spores could be one of the mains reasons for limiting the adoption of HPTS in the food industry.

293 Commercially, HPP has been investigated on a range of different foods, including juices and

294 beverages, fruits, vegetables, ready to eat meals, meat-based products (raw and cooked 295 sausages and dry ham), fish and seafood (Tribst et al. 2016, Georget et al. 2015, Khan et al. 296 2014, Evert-Arriagada et al. 2014). The technology has also been used to replace or assist in 297 the cooking and preservation of meat products (Tribst et al. 2016, http://www.hiperbaric.com/).

298 Furthermore, in dairy sector, the technology has been reported to significantly improve the 299 shelf life of goat's cheese and yoghurt and reduce the allergenicity of milk and ripening time 300 of cheese (Pingen et al. 2016, Zhou, Karwe, and Matthews 2016, Barba et al. 2015).

301 In the last decade, the installation of HPP equipment has increased by around 17\% CAGR across the globe. Sales of HPP systems exceeded more than US\$ 120 million in 2016 and are estimated to exceed US\$ 430 million by the end of 2026 (FMI 2017). HPP manufacturers 304 include Hiperbaric (Spain), Avure Technologies, Inc. (USA), Universal Pasteurization Co. 305 (USA), Next HPP (USA), Engineered Pressure System, Inc. (USA), Chemac, Inc. (USA), 306 Elmhurst Research, Inc. (USA), American Isostatic Pressure, Inc. (USA), Bao Tou Ke Fa High 307 Pressure Technology Co., Ltd. (China), CHIC FresherTech (China), Kobe Steel Ltd. (Japan), 308 Multivac Sepp Haggenmuller SE \& Co. (Germany), Thyssenkrupp AG (Germany) and 309 Stansted Fluid Power Ltd. (UK). Currently more than 352 commercial HPP units which can 310 process 1.065 million metric tons/annum of HPP pasteurized foods are installed worldwide. Of 311 these more than 200 industrial units are currently in operation in North America (Sevenich, 312 Rauh, and Knorr 2016). Hiperbaric, one of the largest manufacturers of HPP units, has installed 313150 industrial units, across 6 continents and over 30 countries. European companies presently 314 employing this technology include UltiFruit, Cinq Degrés Ouest and Delpierre Adrimex in 315 France, Espuña, MRM and Campofríoin Spain and Solofruita, Rovagnati and Ghezzi in Italy 
316 for juice, meat, fish, vegetables, sliced ham and fruit jams (Tsevdou, Eleftheriou, and Taoukis 317 2013, FDA 2015c).

318 Adoption of high pressure processing systems in the food and beverages industry has increased 319 significantly in recent years. Consumer awareness and growing health concerns have significantly increased the demand for organic food and clean label food products. This has resulted in leading industry participants making significant investments in launching such products so as to penetrate the growing market; high pressure processing equipment manufacturers have therefore over the years increased their product variants in terms of capacity either by increasing vessel size or by increasing the number of intensifiers to cater to the technology adoption by the industry (FMI 2017).

\subsection{Pulsed Electric Field Processing}

Pulsed electric field (PEF) is an emerging technology that has been widely studied in recent years for non-thermal food processing. It utilizes short pulses of high electric fields for a short duration (micro- to milliseconds) which pass through the product placed between a set of electrodes inside a PEF chamber (Toepfl et al. 2014, Mohamed, Ayman, and Eissa 2012, Ma et al. 2016, Griffiths and Walkling-Ribeiro 2014, Ozkoc, Sumnu, and Sahin 2014). The electropermeabilization mechanism of PEF has been used for a variety of purposes in food and bioprocessing including the deactivation of microorganisms as well as permeabilization of the cells of the food without thermal effects. The technology is viable for the liquid or semi-solid food products and has successfully been applied for the processing and preservation of foods such as fruit juices, milk, yogurt, soups, cooked meats, liquid eggs and other pumpable food products (Toepfl et al. 2014, Mohamed, Ayman, and Eissa 2012, Ma et al. 2016, Agcam, Akyildiz, and Akdemir Evrendilek 2016, Lohani and Muthukumarappan 2016). However, PEF processing is not suitable for solid food products with no air bubbles which have very low electric conductivity (Griffiths and Walkling-Ribeiro 2014). Apart from food processing, the 
341 technology has been successfully utilized as a novel extraction technique in the area of

342 bioprocessing (Table 1). It has enhanced the yield of potential bioactive compounds and other

343 cellular components from various plants, fruits, vegetables, algae, oil seeds and other food

344 matrices (Griffiths and Walkling-Ribeiro 2014, Toepfl et al. 2014, Shakhova et al. 2015,

345 Amiali and Ngadi 2012). Furthermore, it has also demonstrated a positive influence in the

346 texture of solid plant foods and has found a significant application in reducing the sludge of

347 wastewater (Nasir et al. 2016).

348 Commercially, PEF has been successfully employed for a variety of fruit juices, studies have

349 shown that it causes minimal detrimental effect on in the sensory and physical properties but

350 improves the shelf life and functional and textural attributes of juices (Shakhova et al. 2015,

351 Mohamed, Ayman, and Eissa 2012). Also, it is widely used to reduce the cutting force needed

352 during the production of French fries'. The technique is considered advantageous over

353 traditional thermal processing because it inactivates microorganisms while maintaining the

354 sensory quality and nutritive value of food. The technology is cost effective, energy-efficient,

355 waste free and can easily be implemented into the existing processing lines (Ma et al. 2016,

356 Griffiths and Walkling-Ribeiro 2014, Niemira 2014). While the technology has been

357 successfully commercialized, it still needs more refinement for large scale industrial

358 operations. Currently only a few commercial PEF manufacturers (PurePulse Technologies

359 (Netherlands), KEA-Tec GmbH (Germany), Elea GmbH (Germany), Energy Pulse Systems

360 (Portugal), Montena Technology (Switzerland), Diversified Technologies, Inc. (USA),

361 Pulsemaster (USA) and Thomson-CSF (USA) sell commercial PEF systems. More suppliers

362 are needed to design and construct reliable PEF units (Mohamed, Ayman, and Eissa 2012).

363 Industrial PEF equipment is expensive and has limited treatment capacity. Unavailability of

364 dependable and affordable industrial size equipment and a lack of innovation have limited the

365 industrial adoption of the technology. Successful exploitation of the technique will require the 
identification of a cost or quality benefit to justify the costs of investment, as well as efforts to

367 reduce the cost and most importantly to increase the equipment capacity (Toepfl and Heinz 2007).

\subsection{Cold Plasma Treatment}

370 Cold plasma technology (CPT) is a novel and emerging non-thermal processing technology

371 that uses energetic, reactive gases to inactivate pathogenic and spoilage microorganisms

372 pertinent to food. Plasma is an ionized gas that consists of a large number of different charged

373 species (such as electron, ions, photons and free radicals as well as gas atoms and molecules in their fundamental or excited states) which are produced by providing energy to a neutral gas causing the production of these charged carriers (Misra et al., 2011). Plasma flows around the treated product, causing no shadow effect, ensuring all parts of the product are treated completely. It offers many potential applications for surface decontamination of both food products and food packaging materials. During surface decontamination, microorganisms are exposed to heavily bombard charged species that create surface lesions on the bacterial cell wall causing it to rupture. The technology was initially developed to enhance the surface energy of polymer and sterilization of medical equipment in hospitals (Pankaj et al. 2014, Bahrami et al. 2016, Jayasena et al. 2015). However, it has recently emerged as a powerful disinfection tool for food industry for in-package and post-packaging decontamination of food products including the dry disinfection of solid and liquid food surfaces like dried milk, meat, poultry, fish, herbs, sprouted seeds, grains, spices and fresh produces (Jayasena et al. 2015, Korachi et al. 2015, Misra et al. 2011, Lee et al. 2015, Scholtz et al. 2015). Although different plasma systems are being studied in food packaging and processing, capacity coupled plasma (CCP) sources have gained more attention because of their recent application for enhancing the shelf life and nutritional quality of food products (Table 1) (Schlüter and Fröhling 2014, Mason, Chemat, and Ashokkumar 2015, Bahrami et al. 2016). 
391 While cold plasma technology is gradually gaining acceptance among food processors, the long lasting effect of generated reactive species and their actual mechanism is still unclear. In some

393 cases, reactive species change the morphology of biological cells and cause hindrance in their

394 regular functions (Jayasena et al. 2015), and the role of these active species on some sensitive

395 food constituents such as lipids and vitamins is still ambiguous (Scholtz et al. 2015). Some of

396 the reactive species trigger the oxidation of high lipid containing food products which produce

397 off flavor compounds that cause rancidity. Therefore, meat products are not considered an ideal

398 substrate for plasma treatment (Awad et al. 2012). Nevertheless, cold plasma treatment is an

399 emerging food processing technology which is rapid and does not leave any toxic residuals or

400 exhaust gases post-processing. However, issues regarding the nutritional content, color,

401 texture, chemical changes and overall food quality need to be considered (Mason, Chemat, and

402 Ashokkumar 2015, Korachi et al. 2015).

403 Although, CPT is not fully adopted by the food industry for large scale industrial setting due 404 to the lack of knowledge on some critical parameters, the equipment is readily scalable and has 405 potential for wide-scale applications. Research efforts around the globe are underway to 406 understand the safety of the gases used before bringing it for commercial usage (Awad et al. 407 2012).

\section{$408 \quad 3.4 \quad$ Ultrasound Processing}

409 Ultrasonication has been widely researched and is increasingly employed in the food industry.

410 Ultrasound technology is based on a series of compression and rarefaction cycles induced by 411 sound waves, on the molecules of the medium they pass through, at a frequency above the 412 threshold of human hearing $(>16 \mathrm{kHz})$. These mechanical waves travels through the material 413 or on its surface which leads to the formation of cavitation bubbles. At a high ultrasound power, 414 these bubbles distribute throughout the liquid and at high acoustic pressure they grow to a 415 critical size over a period of a few cycles and violently collapse. This phenomenon leads to 
energy accumulations in hot spots, generates extremely high pressure (up to $100 \mathrm{MPa}$ ) and

417 temperature (up to $5000 \mathrm{~K}$ ) which subsequently produce shear energy shock waves and turbulence in the cavitation zone. Combination of these micro events can induce various physical and chemical properties (such as breakdown the water molecules, disruption of cell wall of biological tissue or polymeric chain of biomolecules) which can be harnessed in food processing (Cheng et al. 2015, Soria and Villamiel 2010). Ultrasound processing is widely employed in the food processing and preservation applications including drying, homogenization, crystallization, defoaming, dispersing, emulsification, solubility and texture enhancement, plant sanitation, viscosity alteration, fermentations, as well as most recently ultrasonication assisted extraction (UAE) of biochemicals from plant tissue and foods (Table 1) (Guamán-Balcázar et al. 2016, Soria and Villamiel 2010, FDA 2015d, Zinoviadou et al. 2015, Ozkoc, Sumnu, and Sahin 2014). The technology has now been adopted for commercial operations across Europe and the USA (Minjares-Fuentes et al. 2016, Guamán-Balcázar et al. 2016). The US food and drug administration (US-FDA) approved the technology as a potential alternative to traditional thermal preservation approach which is capable of achieving a desired $5 \log$ for food borne pathogens and fulfils the requirements for microbial safety in fruit juices (Alarcon-Rojo et al. 2015, Pingret, Fabiano-Tixier, and Chemat 2013). Similarly, ultrasonication assisted extraction of organic compounds from plants, foods or seeds have significantly improved the yield of (heat labile) bioactive compounds (Soria and Villamiel 2010, FDA 2015d).

436 Though, ultrasonic assisted processing, preservation and extraction offers many advantages including suitability for commercial scale-up, studies have reported degradation of food properties including flavor, color, or nutritional value at high amplitude ultrasound treatment (Farkas and Mohácsi-Farkas 2011, Harder, Arthur, and Arthur 2016). Therefore, a better understanding of the complex mechanism of ultrasound and its effect on functional food 
441 properties would advance industry adoption of this technology. In addition, significant

442 improvement in high power process design, improved energy efficiency, easy installation,

443 competitive energy consumption and low maintenance cost need to be considered to make it

444 feasible for large industrial scale-up with worthwhile economic gains (Zinoviadou et al. 2015,

445 Alarcon-Rojo et al. 2015, Pingret, Fabiano-Tixier, and Chemat 2013).

\subsection{Irradiation}

447 Radiation is a non-thermal food preservation process that reduces or eliminates

448 microorganisms without causing harmful changes to the food. The process is considered to be 449 safe under certain conditions and has been approved and adopted by more than 55 countries 450 including USA, European countries, Japan and China (FDA 2012, Urbain 2012). Foods can be 451 considered safe if they are irradiated by one of the following three processes approved by FDA. 452 Gamma rays emitted from radioactive forms of the element cobalt 60 or cesium 137; X-rays 453 produced by reflecting a high-energy stream of electrons off a heavy metals substance or electron beam wherein the high-energy electrons are propelled from an electron accelerator into food (Morehouse and Komolprasert 2004). Gamma or X-rays are high frequency and more powerful than the rays emitted by a microwave oven. They rapidly penetrate the food, inactivate microorganisms, generate no heat hence the nature of the food remain intact. The radiation dose applied to a food material is based upon its composition as well as the potential to harbor microorganisms, however no radioactive waste is produced at the food processing 460 facility.

461 During processing, the food is exposed to radiation for a precise time period and never comes 462 in contact with the radiation source. The process takes very less energy to inactivate 463 microorganisms without increasing the temperature of food product, thus no modification in 464 food quality occurs (Kumar et al. 2016, Marathe et al. 2016, Maloney and Harrison 2016). The process cause minimal modification in the color, flavor, nutrients level, taste, and other quality 
attributes of food. However, this change in food quality is associated with raw material used and the type of radiation source and its dose level applied (Urbain 2012, Gautam, Nagar, and Shashidhar 2015). Nonetheless, in all instances food remains uncooked and none of these energy sources induce radioactivity or leave any residues in the food or its packaging (FDA 2012, Kumar et al. 2016, Rawson et al. 2011).

Irradiation processes may be employed in many applications in the food industry. The technology minimizes the post-harvest loss, retains the color of fresh meat, inhibits sprout formation in products such as potatoes and control post-packaging contamination in a range of food products including cereals, legumes, spices, poultry, fish, seafood, meat, fruits vegetables, tubers and dried vegetable seasonings (Table 1) (Rawson et al. 2011, Urbain 2012, Kumar et al. 2016, Rogers 2010). However irradiation is not suitable for all food types; for instance, milk and high lipid and vitamin content food are unsuitable for irradiation. This is because peroxidation of unsaturated bonds present in the polyunsaturated fatty acids (especially omega 3, C22.5, and C22.6 fatty acids) increases the onset of oxidative rancidity in milk and high lipid 480 foods (Caulfeld, Cassidy, and Kelly 2008). There is conflicting evidence regarding the effect 481 of irradiation on packaging materials. Some reports argue that radiation may react with 482 packaging polymer, printing ink labels or adhesive and can produce low molecular harmful radiolytic hydrocarbons which can transfer into the food product (FDA 2012, Marathe et al. 2016). On the other hand some reports suggest that ionizing radiation process has a potential to overcoming quarantine barriers for international trade in fresh fruits and vegetables (Urbain 2012, Vieites and Calvo 2011). Despite its limited use to date, industrial adoption of the technique is increasing as consumers are beginning to appreciate the benefits of irradiated food. Interest in the use of food irradiation increased when the US Food and Drug Administration (FDA) approved the irradiation of unprocessed red meat and meat products for pathogen control in 1997 (Morehouse and Komolprasert 2004). To ensure the safety of product, food 
authorities have introduced a number of detection methods which focus on selected chemical,

492 physical or biological changes that could occur in treated foods (Kumar et al. 2016). The

493 consensus of opinion is that, within the prescribed dose limit, the process is safe and causes no

494 significant damage to nutritional quality (FDA 2012, Marathe et al. 2016).

\subsection{UV and Pulsed Light}

496 Techniques like ultraviolet (UV) and pulsed light (PL) light are innovative minimal food

497 processing technologies that improve the safety of food products, maintain their appearance

498 and nutrient content while extending their shelf life. (Cheigh et al. 2012, Abida, Rayees, and

499 Masoodi 2014, Koutchma et al. 2016). UV technology utilizes shorter wavelength light of

500 (100-380 nm) while pulsed light works on broad spectrum of light (180-1100 nm). However,

501 the lethal effect of both UV and pulsed light is attributed to the UV part of the spectrum and its

502 photochemical, photothermal and physical mechanism. The damage of microbial cell wall after

503 the treatment is so severe that its DNA repair system is affected and enzymatic functions are

504 affected which leads to a collapse of cell structure due to increased cell membrane permeability

505 and depolarization of cell membrane (Elmnasser et al. 2007).

506 UV technology was originally used in Europe to disinfect municipal drinking water as an

507 alternative to chlorination but now it is applied globally for the treatment of drinking water, wastewater, process water and industrial affluent (Forney and Moraru 2009, Demirci and Ngadi 2012, Koutchma 2014). The use of UV light as an alternative treatment to thermal

510 pasteurization of fresh juices has been approved by the USFDA (IFT 2000). UV systems are

511 low maintenance, environmentally friendly and can be installed at any point along a process system, with minimum disruption to the plant. Commercially, UV is already a well-established

513 disinfection method in pharmaceutical manufacturing and now is rapidly gaining acceptance

514 across food and beverage industries. It is demonstrated to be effective against bacterial 515 pathogens in liquid foods, and it neither increases the temperature of the product not produces 
undesirable organoleptic changes (Oteiza, Giannuzzi, and Zaritzky 2010, Gabriel 2012). The

517 technology (UV-C, $\lambda=254 \mathrm{~nm}$ ) achieves microbial inactivation by radiant exposure of at least

$518400 \mathrm{~J} / \mathrm{m}^{2}$ in all parts of the product (IFT 2000). Besides, its new industrial applications and

519 innovative treatments are being studied and developed continuously (Forney and Moraru 2009,

520 Hamanaka et al. 2011, Koutchma 2014).

521 Similarly, pulsed light (PL) technology is an emerging non-thermal technology and appears to

522 be one of the best alternatives to conventional thermal heating for decontamination of food

523 surfaces and food packages. The technology can be described as a sterilization or 524 decontamination technique used mainly to inactivate surface micro-organisms on foods, 525 packaging material and equipment (Abida, Rayees, and Masoodi 2014). It exposes the 526 substrate to intense short time high-peak pulses of broad spectrum white light in concentrated 527 form and is considered an alternative to continuous ultraviolet light treatments for solid and 528 liquid foods. While this technology inactivates bacteria, fungi, and viruses more rapidly and 529 effectively than continuous UV treatment (Elmnasser et al. 2007, Cheigh et al. 2012) and has better sterilization properties than UV light, pulsed light sterilization has a relatively low 531 penetration depth in comparison to continuous ultraviolet light (UV). This limits its use to the 532 surface decontamination of foods, packaging materials, and food contact surfaces, and the 533 sterilization of certain liquids (Hierro et al. 2009, Oms-Oliu, Martín-Belloso, and Soliva534 Fortuny 2010, Abida, Rayees, and Masoodi 2014). The mechanism by which pulsed light induces cell death has yet to be fully explained, but the general consensus is that the UV region

536 of the broad spectrum of pulsed light can inactivate microorganisms by chemical modification 537 and cleavage of its DNA (Oms-Oliu, Martín-Belloso, and Soliva-Fortuny 2010, Dhineshkumar, 538 Ramasamy, and Kumar 2015). In most cases, the technology doesn't alter the treated material 539 thus legal approval is easier, however a detailed analytical study is required for each new PL 
treated food and that needs to follow the legal framework designed by FDA for radiationtreated foods for its commercial usage (Forney and Moraru 2009).

542 The effect of thermal and non-thermal processing on nutritional quality, physico-chemical properties and sensorial characteristic may further validate the use of emerging processing techniques as an upcoming tool for food processing industry. Although, all different food processing techniques have their own benefits and limitations, more research is required to facilitate food equipment manufacturers realize their potential for successful applications in the food industry. Advantages, limitations and commercial applications of emerging thermal and non-thermal technologies are described in Table 1.

\section{ADOPTION OF NOVEL TECHNOLOGIES BY INDUSTRY}

550 The adoption and incorporation of newly developed technologies by industry is a key measure of successful technology development. Rogers (2010) outlined key factors that influence novel technology adoption by industry. These include the relative advantage of the new technology; ease of adoption compared to alternative options; level of technology complexity and perception of the technology. The adoption of novel technologies can be viewed as a process of organizational change that impacts the technical and social systems of an organization (Vieites and Calvo 2011). It is consisting of two main stages: initiation and implementation

(Fig. 3), with the initiation stage can be further categorized as three sub-stages: awareness of a novel technique; formation of an attitude towards it; and its evaluation from an organizational standpoint (Novoselova, Meuwissen, and Huirne 2007). Rollin et al. (2011) suggest that the decision to adopt a novel technology marks the beginning of the implementation stage, which can also be categorized into two sub stages: trial implementation and sustained implementation. organizational needs while sustained implementation, the final stage of the adoption process, 
involves the complete assimilation of the technology into the organization. The series of decision making involved, often includes a comparative analysis of the uncertain benefits of the novel technique and of the uncertain costs of adopting it. While the benefits from adopting a new technology are ongoing and are exploited throughout the life of the acquired novel technology, costs including the fixed costs of adoption or costs associated with technical knowhow, are primarily incurred at the time of adoption and cannot be recovered (Rivas 2010).

Industrial usage of the new technology may require initial investment, modification of manufacturing processes and specialized staff training. Consequently, unless new technologies can provide cost and/or performance advantages relative to existing technologies in use, their adoption by industry is unlikely (Suri 2011). When considering the possible adoption of new technologies companies evaluate potential benefits and associated risks, uncertainty of usage, and the cost of any management and production changes necessitated by the adoption (Long, Blok, and Coninx 2016). The success of the adoption of a novel technology is therefore estimated by the degree of likely integration of the technology into an organization and its potential contribution to key business objectives.

579 The technology, organization and environment framework describing the technology context, influence technology adoption by an enterprise. The technology context includes the internal practices and equipment of a company as well as the external technologies available to the company (Tornatzky, Fleischer, and Chakrabarti 1990). The organizational context refers to the managerial structures, scope and size of the company while the environmental context

584 includes the industry, competitors and policy frameworks (Oliveira and Martins 2010). Furthermore, the investigation of psychological, social, political and historical issues is an essential element of commercialization of novel technologies (Frewer et al. 2011). Patist \& Bates (2008) and Suri (2011) outlined that industrial adoption of any technology is often guided by the following commercial considerations : 
589 a) The monetary and intellectual property appeal of the technology.

590 b) The economical need or the payback schedule of the industry. For instance in many

591 industries the maximum payback time is shorter when the risk is higher.

592 c) The scalability and reliability of the novel technology and its implementations elsewhere.

593 d) A complete road map to technology adoption (including cost, time and resources required).

594 This helps manage expectations and ensures a good understanding of what the technology

595 adoption involves both in terms of investment and returns.

596 e) Usually the adoption of a new technology in an existing production facility means a 597 provisional shutdown or production slow down. It is therefore important that managers 598 understand the benefits of the implementation and maximize the adoption value during the 599 implementation or overlap period.

600 f) The cultural appropriateness of integrating a novel technology also guides its adoption.

601 Thus the adoption a new technology by the industry, as depicted in the Fig. 4, can be seen as

602 the collection or aggregate outcome of a range of individual calculations that estimate the 603 incremental benefits of a new technology adoption verses the expense of changes it involves.

604 The analysis consists an uncertain environment with limited information; ambiguous 605 environment with regard to the future evolution of the technology and its benefits and minimal 606 information about both the benefits and costs of the technology (Biagini et al. 2014, Gatignon 607 and Robertson 1989). An understanding of the industrial adoption of new technologies is 608 therefore an important aspect in achieving commercial success. 
611 The costs of adoption and benefits received by the users are the most observable determinants

612 of new technology adoption. These benefits in the case of companies are generally the

613 difference in profits when a company shifts from an existing to a new technology. As consumer

614 acceptance is one of the vital considerations for industry when adopting a new technology,

615 companies need to evaluate the perceived benefits and risks (health, economic, social, and

616 environmental) as perceived by consumers. Ethical concerns, regulatory frameworks,

617 differential accruement of risks and benefits and socio-cultural differences are other points of 618 consideration (Frewer et al. 2011). For instance, while the application of irradiation for food 619 preservation has been approved by the US Food and Agriculture Organization, its usage is 620 limited due to lack of consumer awareness and public perception. Factors other than public acceptance, that influence the adoption of new technologies by industry have been explored in previous research (Milliou and Petrakis 2011, Genius et al. 2013). These factors include availability of resources and technical skills, customer relations, company size, market share and regulatory issues. Additionally, factors pertaining to the competitive environment of the

625 industry and its information processing characteristics also play a role in the adoption of novel technologies (Siegrist 2008, Rivas 2010). Thus overarchingly these factors can be categorized as social, environmental, economic and technological factors.

\subsection{Economic and Technological Factors}

\subsubsection{Availability of Resources and Complementary Skills}

630 Capital goods and skilled work force are critical in successful adoption and implementation of 631 a new technology. Important complementarities between adoption of novel technologies and training for skill development specific to the technology are essential (Boothby, Dufour, and 
633 Tang 2010). Technology that is expensive to implement and requires complex new skills or if 634 acquiring the skills is time-consuming or costly then the adoption of the technology tends to be 635 slow (Novoselova, Meuwissen, and Huirne 2007, Long, Blok, and Coninx 2016). Thus 636 technical know-how, availability of the necessary skills and the manner in which the required 637 skills can be developed are important determinants of adoption of new technologies by 638 industry. For instance, while RF is widely employed in industrial applications, it is still not 639 considered an indispensable heating technology due to its high operational cost and other 640 technical challenges including dielectric breakdown and thermal runaway heating (FDA 641 2015a). Furthermore, the dielectric property information of many food products is not available 642 for the RF region which has limited the full commercialization of this technology in food 643 processing (Maloney and Harrison 2016).

644 Nemoto, Vasconcellos, \& Nelson (2010) emphasized that industrial adoption of a novel 645 technology also depends on the technical capacity of an industry. If the proposed technology 646 is too advanced relative to the technical capacity of the industry then implementing the 647 technology would be a much longer and complex process. Often high fixed costs and 648 infrastructural requirements restrict adoption of novel technologies (Suri 2011).

\subsubsection{Company Size and Market Share}

650 It has been argued that company size and market share have a positive role in determining the 651 adoption of novel technologies by industries (Cullen, Forbes, and Grout 2013). Companies 652 with larger market share are more likely to adopt a new technology because of the availability 653 of funds and enhanced ability to generate profits from the adoption. Larger and more profitable companies are better equipped with the financial resources required for purchase and installation of new technology. Companies with sufficient market power are more likely to find 656 it profitable to adopt a new technology. Also, these companies may be more likely to attract 657 the required human capital and other important resources that may be required. Many new 
technologies that are scale-enhancing are quickly adopted by larger companies so as to capture economies of scale from production and spread the associated fixed costs across a larger number of units.

661 However, there are alternative arguments that large size and market power may also impede

662 the adoption of new technologies by industries. Firstly, multiple levels of bureaucracy in larger

663 companies may obstruct the decision making processes about new concepts, and skills and

664 resources required. Secondly, the argument that older and larger companies may find it 665 relatively more expensive to adopt a new technology due to large sunk costs in their current 666 resources and human capital (Vieites and Calvo 2011).

\section{$667 \quad 5.1 .3$ Competitive Environment of the Industry}

668 Companies are always impacted by technology adoption decisions of their competitors 669 (Doraszelski 2004, Kapoor and Lee 2013). For example, the Irish marine biotechnology 670 company, Little Samphire Island company outperforms the competition by using an unique bio 671 refinery/ integrated manufacturing process to manufacture a range of high value products 672 derived from marine algae (Teagasc 2016). Novel technology adoption therefore is 673 significantly influenced by strategic interactions with competitors in manners like (i) Industry 674 concentration; (ii) Competitive price intensity, (iii) Demand uncertainty and (iv) Supplier 675 customer co-ordination.

\subsection{Environmental Factors}

\section{$677 \quad 5.2 .1 \quad$ Regulatory Compliance}

678 New technology adoption is often impacted by the regulatory environment. Food safety issues 679 including inactivation of pathogenic microorganisms, processing induced chemicals, as well as 680 interaction effects between the process, packaging and product need to be evaluated. For 681 instance reactive species responsible for providing microbial safety of cold plasma processed 
682 food can change the morphology and regulatory function of biological cells and therefore this

683 must be examined (Jayasena et al. 2015). Similarly some studies have reported food safety

684 risks of irradiation that it reacts with packaging material, printing ink and labels producing

685 harmful radiolytic compounds that can contaminate food products (Marathe et al. 2016).

686 Independent data is therefore primarily required to endorse, with a high degree of certainty,

687 that the safety requirements of the regulatory agencies are met by the products. However, the

688 precision and consistency demanded for confirming safety and regulatory compliance, together

689 with the high accompanying cost, often slowdown or discourage commercialization and

690 therefore the application of the novel processing technologies (Koutchma and Keener 2015).

691 Golembiewski et al. (2015) suggest that the rate of new technology adoption is contingent on

692 development of new industry standards. In Europe, the Novel Food Regulation (EC 258/97)

693 may be regarded as a significant example of laws being framed to meet the demand of

694 legislative tools arising from technological innovations (Van Der Meulen 2011). Government

695 policies to encourage new technology adoption are often designed as tax incentives to

696 encourage industry investments in machinery and equipment pertaining to the novel

697 technology. Another way by which government policies encourage new technology adoption

698 is by state's investment in related infrastructure to support the industries (Boothby, Dufour,

699 and Tang 2010). Optimal policy measures towards technology adoption also impacts the speed

700 of its adoption e.g., by way of academic-industry research joint undertakings, where costs of

701 bringing the new technology to market is reduced by contribution from public research labs,

702 speeding up of the new technology adoption is achieved (Milliou and Petrakis 2011). 


\subsection{Social Factors}

704

705

706

707

708

709

710

711

712

713

714

715

716

717

718

719

720

721

722

723

724

725

726

727

\subsubsection{Consumer Acceptability}

While a range of new technologies are continuously being developed with a promise of more efficient production and better quality for consumers, their industrial adoption and implementation is strongly impacted by consumers' acceptability (Fig. 5). Limited acceptance of a technology by consumers in turn affects its adoption at industry level (Golembiewski, Sick, and Bröring 2015). Previous research on consumer attitudes towards novel technologies highlights that consumer acceptance depends on whether consumers perceive benefits associated with the product and largely define the success/survival of the product on retail shelves and consequently an adoption by industries (Frewer et al. 2011, Olsen, Grunert, and Sonne 2010, Rollin, Kennedy, and Wills 2011). Many risk-benefit perceptions influence consumers' acceptance of new technologies related to their food (Golembiewski, Sick, and Bröring 2015). Research also suggest that while perceived benefits drive technology acceptance by consumers, lack of these result in accentuating concerns and perceived risks about the novel technology (Frewer et al. 2011, Rollin, Kennedy, and Wills 2011, Siegrist 2008). Other factors that impact new technology acceptance by consumers' range from sociodemographic attributes to knowledge and information about the technology, as well as trust in the source of the information (Rollin, Kennedy, and Wills 2011, Long, Blok, and Coninx 2016, Johnson 2010).

Nowadays consumers are more health cautious and focused on what they eat and how it is produced compared to a few decades ago. For example because of consumer attitudes, many processing technologies are either delayed (e.g. genetically engineered foods) or limited (e.g. ionizing radiation) (Frewer et al. 2011, Olsen, Grunert, and Sonne 2010). A survey conducted on 609 consumers across Norway, Denmark, Hungary, and Slovakia showed that European consumers have a positive view on HPP and PEF treated juice alternatives to pasteurized juice 
728 if the price is right (Olsen et al. 2011). Similarly, potential consumers from Australia and US were interested in new food processing technologies and willing to pay for new food products treated by these technologies. However, their primary willingness was to have safety and benefits statement on to the product and the risks associated with the technology applied. Among the consumers, female participants were more concerned about the safety of technology and their expected liking ratings were positively influenced by visual exposure to the product (Cardello, Schutz, and Lesher 2007, Cox and Evans 2008, Frewer et al. 2011). Thus consumer awareness and consequently their demands have forced the legislators, retailers and food and technology manufacturers to value their opinion and take it into consideration even when it is not based on a sound technical understanding of the concept.

\subsubsection{Customer Relations of Industry}

739 Having a stable and secure customer base is another important factor impacting the adoption 740 of novel technologies by industries. As a way of reducing the risk inherent in adoption, companies' decision is impacted by the stability of its customer bases which is seen as a way to recover high expenditure incurred in the adoption new technologies (Rollin, Kennedy, and Wills 2011). In some cases, even if a technology has the potential of improving productivity or product quality, companies might not adopt due to potential cost of production shut down for new installations and the uncertainty of recovering adoption costs in presence of uncertain market scenarios (Long, Blok, and Coninx 2016, Sonne et al. 2012, Olsen, Grunert, and Sonne 2010). However, having a committed customer base can impact this decision in a favorable manner.

\section{CONCLUDING REMARKS}

750 This review of trends in food processing technologies discusses the emerging innovative food 751 processing technologies and highlights various factors influencing adoption of such novel 
innovative technologies. New technologies are needed by the food industry to meet the challenges of increased competition, globalization and the growing dynamic and varied consumer demands. Emerging food processing technologies are offering sophisticated solutions to some of these challenges and meeting the consumer preferences. In contrast to traditional technologies, these novel technologies are not well accepted by industry or consumers. It is attributed that the consumers' attitude towards novel food technologies are uncertain, unknown or unfamiliar which is associated with the risk perception. Especially when some processing technologies are connected to adverse perceptions associated with the radiations. These lead to unacceptability by consumers and consequently by industry. Additionally, as detailed above, some technologies require high initial investments, expensive equipment and/or other constraints and limitations. The development of food processing technologies appears to be a long-term trend with important market potential, where research and innovations are needed to be supported by industrial investments, adoption decisions and government regulations. These innovative technologies not only present an opportunity for the development of new foods but by way of milder processing these can also improve the safety and quality of conventional foods. Additionally the different physical phenomena that these technologies utilize can potentially reduce energy and water consumption, which in turn can aid in decreasing the carbon and water footprint of food processing, thereby working towards toward environmental sustainability and global food security.

771 While this review details the various innovative thermal and non-thermal food processing 772 technologies in terms of their mechanisms, applications and commercial aspects, it also outlines that at industry level, the technological capabilities of individual companies, their size, market share as well as their absorptive capacity can impact adoption. Characteristics of the technology itself such as costs involved in its development and commercialization, associated risks and relative advantage, its level of complexity and compatibility are also important. 
Previous research has also outlined that adoption of novel technologies is marred by challenges

778

779

780

781

782

783

784

785

786

787

788

789

790

791

792

793

794

795

796

797

798

799

800

801

802

803

804

805

806

807

808

809

810

811

812

813

814

815

both on the demand and supply side; therefore a detailed exploration and understanding of the

development and application of innovative technologies along with that of factors influencing

their adoption are crucial for their technological and commercial success.

\section{Acknowledgments}

None

\section{References}

Abida, J, B Rayees, and FA Masoodi. 2014. "Pulsed light technology: a novel method for food preservation." International Food Research Journal no. 21 (3).

Agcam, E., A. Akyildiz, and G. Akdemir Evrendilek. 2016. "A comparative assessment of long-term storage stability and quality attributes of orange juice in response to pulsed electric fields and heat treatments." Food and Bioproducts Processing no. 99:90-98. doi: http://dx.doi.org/10.1016/j.fbp.2016.04.006.

Ahmed, Jasim, and Hosahalli S Ramaswamy. 2004. "Microwave pasteurization and sterilization of foods." Food Science and Technology-New York-Marcel Dekker- no. 167:691.

Alarcon-Rojo, A. D., H. Janacua, J. C. Rodriguez, L. Paniwnyk, and T. J. Mason. 2015. "Power ultrasound in meat processing." Meat Science no. 107:86-93. doi: http://dx.doi.org/10.1016/j.meatsci.2015.04.015.

Alfaifi, Bandar, Shaojin Wang, Juming Tang, Barbara Rasco, Shyam Sablani, and Yang Jiao. 2013. "Radio frequency disinfestation treatments for dried fruit: Dielectric properties." LWT-Food Science and Technology no. 50 (2):746-754.

Amiali, M., and M. O. Ngadi. 2012. "14 - Microbial decontamination of food by pulsed electric fields (PEFs)." In Microbial Decontamination in the Food Industry, 407-449. Woodhead Publishing.

Awad, T. S., H. A. Moharram, O. E. Shaltout, D. Asker, and M. M. Youssef. 2012. "Applications of ultrasound in analysis, processing and quality control of food: A review." Food Research International no. 48 (2):410-427. doi: http://dx.doi.org/10.1016/j.foodres.2012.05.004.

Awuah, George B, Hosahalli S Ramaswamy, and Juming Tang. 2014. Radio-Frequency Heating in Food Processing: Principles and Applications: CRC Press.

Bahrami, Niloufar, Danny Bayliss, Gemma Chope, Simon Penson, Tania Perehinec, and Ian D. Fisk. 2016. "Cold plasma: A new technology to modify wheat flour functionality." Food Chemistry no. 202:247-253. doi: http://dx.doi.org/10.1016/j.foodchem.2016.01.113.

Barba, Francisco J., Oleksii Parniakov, Sofia A. Pereira, Artur Wiktor, Nabil Grimi, Nadia Boussetta, Jorge A. Saraiva, Javier Raso, Olga Martin-Belloso, Dorota WitrowaRajchert, Nikolai Lebovka, and Eugène Vorobiev. 2015. "Current applications and new opportunities for the use of pulsed electric fields in food science and industry." Food 
Research International no. 77, Part 4:773-798. doi: http://dx.doi.org/10.1016/j.foodres.2015.09.015.

Barbosa-Cánovas, Gustavo V, and P Juliano. 2008. "Food sterilization by combining high pressure and thermal energy." In Food engineering: Integrated approaches, 9-46. Springer.

Bastías, J. M., J. Moreno, C. Pia, J. Reyes, R. Quevedo, and O. Muñoz. 2015. "Effect of ohmic heating on texture, microbial load, and cadmium and lead content of Chilean blue mussel (Mytilus chilensis)." Innovative Food Science \& Emerging Technologies no. 30:98-102. doi: http://dx.doi.org/10.1016/j.ifset.2015.05.011.

Bengtson, R., E. Birdsall, S. Feilden, S. Bhattiprolu, S. Bhale, and M. Lima. 2006. "Ohmic and Inductive Heating." In Handbook of Food Science, Technology, and Engineering, edited by Y. H. Hui, 120.1-120.7. Boca Raton, FL, USA: CRC Press, Tayler and Francis Group.

Bermúdez-Aguirre, Daniela, and Gustavo V Barbosa-Cánovas. 2011. "An update on high hydrostatic pressure, from the laboratory to industrial applications." Food Engineering Reviews no. 3 (1):44-61.

Biagini, Bonizella, Laura Kuhl, Kelly Sims Gallagher, and Claudia Ortiz. 2014. "Technology transfer for adaptation." Nature Climate Change no. 4 (9):828-834.

Boothby, Daniel, Anik Dufour, and Jianmin Tang. 2010. "Technology adoption, training and productivity performance." Research Policy no. 39 (5):650-661.

Boye, Joyce I, and Yves Arcand. 2013. "Current trends in green technologies in food production and processing." Food Engineering Reviews no. 5 (1):1-17.

Capitanio, Fabian, Adele Coppola, and Stefano Pascucci. 2010. "Product and process innovation in the Italian food industry." Agribusiness no. 26 (4):503-518.

Cardello, Armand V, Howard G Schutz, and Larry L Lesher. 2007. "Consumer perceptions of foods processed by innovative and emerging technologies: A conjoint analytic study." Innovative Food Science \& Emerging Technologies no. 8 (1):73-83.

Caulfeld, Catherine D, Joseph P Cassidy, and John P Kelly. 2008. "Effects of gamma irradiation and pasteurization on the nutritive composition of commercially available animal diets." Journal of the American Association for Laboratory Animal Science no. 47 (6):61-66.

Cheigh, Chan-Ick, Mi-Hyun Park, Myong-Soo Chung, Jung-Kue Shin, and Young-Seo Park. 2012. "Comparison of intense pulsed light-and ultraviolet (UVC)-induced cell damage in Listeria monocytogenes and Escherichia coli O157: H7." Food Control no. 25 (2):654-659.

Chen, Jiajia, Krishnamoorthy Pitchai, Sohan Birla, David Jones, Mehrdad Negahban, and Jeyamkondan Subbiah. 2016. "Modeling heat and mass transport during microwave heating of frozen food rotating on a turntable." Food and Bioproducts Processing no. 99:116-127. doi: http://dx.doi.org/10.1016/j.fbp.2016.04.009.

Chen, Qing, Sven Anders, and Henry An. 2013. "Measuring consumer resistance to a new food technology: A choice experiment in meat packaging." Food Quality and Preference no. 28 (2):419-428.

Cheng, Xinfeng, Min Zhang, Baoguo Xu, Benu Adhikari, and Jincai Sun. 2015. "The principles of ultrasound and its application in freezing related processes of food materials: A review." Ultrasonics sonochemistry no. 27:576-585.

Cho, Won-Il, Ji Yoon Yi, and Myong-Soo Chung. 2016. "Pasteurization of fermented red pepper paste by ohmic heating." Innovative Food Science \& Emerging Technologies no. 34:180-186. doi: http://dx.doi.org/10.1016/j.ifset.2016.01.015. 
Chua, Kian Jon, and Siaw Kiang Chou. 2014. "Chapter 24 - Recent Advances in Hybrid Drying Technologies A2 - Sun, Da-Wen." In Emerging Technologies for Food Processing (Second Edition), 447-459. San Diego: Academic Press.

Cox, DN, and G Evans. 2008. "Construction and validation of a psychometric scale to measure consumers' fears of novel food technologies: The food technology neophobia scale." Food Quality and Preference no. 19 (8):704-710.

Cullen, Ross, Sharon L Forbes, and Rachel Grout. 2013. "Non-adoption of environmental innovations in wine growing." New Zealand Journal of Crop and Horticultural Science no. 41 (1):41-48.

Darvishi, Hosain, Adel Hosainpour, Farzad Nargesi, and Ali Fadavi. 2015. "Exergy and energy analyses of liquid food in an Ohmic heating process: A case study of tomato production." Innovative Food Science \& Emerging Technologies no. 31:73-82. doi: http://dx.doi.org/10.1016/j.ifset.2015.06.012.

Deeth, H. C., and N. Datta. 2011. "Heat Treatment of Milk|Ultra-High Temperature Treatment (UHT): Heating Systems A2 - Fuquay, John W." In Encyclopedia of Dairy Sciences (Second Edition), 699-707. San Diego: Academic Press.

Demirci, Ali, and Michael O Ngadi. 2012. Microbial decontamination in the food industry: Novel methods and applications: Elsevier.

Dhineshkumar, V, D Ramasamy, and C Ashok Kumar. 2015. "High Intensity Pulsed Light Technology in Food Preservation." The International Journal of Science and Technoledge no. 3 (3):149.

Doraszelski, Ulrich. 2004. "Innovations, improvements, and the optimal adoption of new technologies." Journal of Economic Dynamics and Control no. 28 (7):1461-1480.

Duygu, Balpetek, and Gürbüz Ümit. 2015. "Application of Ohmic Heating System in Meat Thawing." Procedia - Social and Behavioral Sciences no. 195:2822-2828. doi: http://dx.doi.org/10.1016/j.sbspro.2015.06.400.

Elmnasser, Noura, Sandrine Guillou, Francoise Leroi, Nicole Orange, Amina Bakhrouf, and Michel Federighi. 2007. "Pulsed-light system as a novel food decontamination technology: a review." Canadian journal of microbiology no. 53 (7):813-821.

Evert-Arriagada, K., M. M. Hernández-Herrero, B. Guamis, and A. J. Trujillo. 2014. "Commercial application of high-pressure processing for increasing starter-free fresh cheese shelf-life." LWT - Food Science and Technology no. 55 (2):498-505. doi: http://dx.doi.org/10.1016/j.lwt.2013.10.030.

Falguera, Víctor, Núria Aliguer, and Mercè Falguera. 2012. "An integrated approach to current trends in food consumption: Moving toward functional and organic products?" Food Control no. 26 (2):274-281.

Farkas, József, and Csilla Mohácsi-Farkas. 2011. "History and future of food irradiation." Trends in Food Science \& Technology no. 22 (2-3):121-126. doi: http://dx.doi.org/10.1016/j.tifs.2010.04.002.

FDA. 2012. "Irradiation in the production, processing and handling of food. Final rule." Federal register-Food and Drug Administration, HHS no. 73 (164):49593.

FDA. 2015a. Kinetics of microbial inactivation for alternative food processing technologiesmicrowave and radio frequency processing. edited by Food and Drug Administration. USA.

FDA. 2015b. Kinetics of Microbial Inactivation for Alternative Food Processing Technologies -- Ohmic and Inductive Heating. edited by Food and Drug Administration. USA.

FDA. 2015c. Kinetics of Microbial Inactivation for Alternative Food Processing TechnologiesPulsed Electric Fields. edited by Food and Drug Administration. USA.

FDA. 2015d. Kinetics of Microbial Inactivation for Alternative Food Processing Technologies - Ultrasound. edited by Food and Drug Administration. USA. 
914 Fellows, Peter J. 2009. Food processing technology: principles and practice: Elsevier.

915 Fischer, ARH, HCM van Trijp, D Hofenk, A Ronteltap, and Ana Alina Tudoran. 2013. "Collation of Scientific Evidence on Consumer Acceptance of New Food Technologies: Three roads to consumer choice." Recapt-EU FP7.

FMI. 2017. High Pressure Processing Equipment Market: MEA Region Projected to Witness Sluggish Growth in Terms of Value and Volume Throughout the Forecast Period: Global Industry Analysis \& Opportunity Assessment, 2016-2026. Future Market Insights.

Forney, Larry J, and Carmen I Moraru. 2009. Ultraviolet light in food technology: principles and applications: CRC press.

Fowler, Matthew R., and Jae W. Park. 2015. "Effect of salmon plasma protein on Pacific whiting surimi gelation under various ohmic heating conditions." LWT - Food Science and Technology no. 61 (2):309-315. doi: http://dx.doi.org/10.1016/j.lwt.2014.12.049.

Frewer, LJ, K Bergmann, M Brennan, R Lion, R Meertens, G Rowe, M Siegrist, and C Vereijken. 2011. "Consumer response to novel agri-food technologies: implications for predicting consumer acceptance of emerging food technologies." Trends in Food Science \& Technology no. 22 (8):442-456.

Gabriel, Alonzo A. 2012. "Inactivation of Escherichia coli O157: H7 and spoilage yeasts in germicidal UV-C-irradiated and heat-treated clear apple juice." Food Control no. 25 (2):425-432.

Gatignon, Hubert, and Thomas S Robertson. 1989. "Technology diffusion: an empirical test of competitive effects." The Journal of Marketing:35-49.

Gautam, Raj Kamal, Vandan Nagar, and Ravindranath Shashidhar. 2015. "Effect of radiation processing in elimination of Klebsiella pneumoniae from food." Radiation Physics and Chemistry no. 115:107-111.

Genius, Margarita, Phoebe Koundouri, Céline Nauges, and Vangelis Tzouvelekas. 2013. "Information transmission in irrigation technology adoption and diffusion: social learning, extension services, and spatial effects." American Journal of Agricultural Economics:aat054.

Georget, E., R. Sevenich, K. Reineke, A. Mathys, V. Heinz, M. Callanan, C. Rauh, and D. Knorr. 2015. "Inactivation of microorganisms by high isostatic pressure processing in complex matrices: A review." Innovative Food Science \& Emerging Technologies no. 27:1-14. doi: http://dx.doi.org/10.1016/j.ifset.2014.10.015.

Golembiewski, Birte, Nathalie Sick, and Stefanie Bröring. 2015. "The emerging research landscape on bioeconomy: What has been done so far and what is essential from a technology and innovation management perspective?" Innovative Food Science \& Emerging Technologies no. 29:308-317.

Goullieux, Adeline, and Jean-Pierre Pain. 2014. "Ohmic Heating." In Emerging Technologies for Food Processing (Second Edition), edited by Da-Wen Sun, 399-426. San Diego: Academic Press.

Griffiths, Mansel W., and Markus Walkling-Ribeiro. 2014. "Pulsed Electric Field Processing of Liquid Foods and Beverages." In Emerging Technologies for Food Processing (Second Edition), edited by Da-Wen Sun, 115-145. San Diego: Academic Press.

Guamán-Balcázar, MC, W Setyaningsih, M Palma, and CG Barroso. 2016. "Ultrasoundassisted extraction of resveratrol from functional foods: cookies and jams." Applied Acoustics no. 103:207-213.

Ha, Jae-Won, Sung-Youn Kim, Sang-Ryeol Ryu, and Dong-Hyun Kang. 2013. "Inactivation of Salmonella enterica serovar Typhimurium and Escherichia coli O157:H7 in peanut butter cracker sandwiches by radio-frequency heating." Food Microbiology no. 34 (1):145-150. doi: http://dx.doi.org/10.1016/j.fm.2012.11.018. 
Hamanaka, Daisuke, Naoko Norimura, Noriko Baba, Kozo Mano, Makoto Kakiuchi, Fumihiko Tanaka, and Toshitaka Uchino. 2011. "Surface decontamination of fig fruit by combination of infrared radiation heating with ultraviolet irradiation." Food Control no. $22(3-4): 375-380$.

Harder, M. N. C., V. Arthur, and P. B. Arthur. 2016. "Irradiation of Foods: Processing Technology and Effects on Nutrients: Effect of Ionizing Radiation on Food Components." In Encyclopedia of Food and Health, 476-481. Oxford: Academic Press.

Henchion, M, M McCarthy, G Greehy, S McCarthy, E Dillon, G Kavanagh, and G Williams. 2013. Irish Consumer and industry acceptance of novel food technologies: Research highlights, implications \& recommendations. Ashtown (Dublin), Ireland: Teagasc Food Research Centre.

Hierro, Eva, Susana Manzano, Juan A Ordóñez, Lorenzo de la Hoz, and Manuela Fernández. 2009. "Inactivation of Salmonella enterica serovar Enteritidis on shell eggs by pulsed light technology." International Journal of Food Microbiology no. 135 (2):125-130.

http://www.hiperbaric.com/. High Pressure Processing for food \& beverage products [cited 28-05-2016. Available from http://www.hiperbaric.com/en.

Huang, Hsiao-Wen, Chiao-Ping Hsu, Binghuei Barry Yang, and Chung-Yi Wang. 2014. "Potential Utility of High-Pressure Processing to Address the Risk of Food Allergen Concerns." Comprehensive Reviews in Food Science and Food Safety no. 13 (1):78-90. Huang, Zhi, Francesco Marra, and Shaojin Wang. 2016. "A novel strategy for improving radio frequency heating uniformity of dry food products using computational modeling." Innovative Food Science \& Emerging Technologies no. 34:100-111. doi: http://dx.doi.org/10.1016/j.ifset.2016.01.005.

Hussein, F. Hassan, Tola Yetenayet, and S. Ramaswamy Hosahalli. 2014. "Radio-Frequency and Microwave Applications: Similarities, Advantages, and Limitations." In RadioFrequency Heating in Food Processing, 21-30. CRC Press.

IFT. 2000. Kinetics of microbial inactivation for alternative food processing technologies: Institute of Food Technologists.

Ito, Ruri, Mika Fukuoka, and Naoko Hamada-Sato. 2014. "Innovative food processing technology using ohmic heating and aseptic packaging for meat." Meat Science no. 96 (2, Part A):675-681. doi: http://dx.doi.org/10.1016/j.meatsci.2013.10.012.

James, S. J., and C. James. 2014. "COOKING OF MEAT | Heat Processing Methods." In Encyclopedia of Meat Sciences (Second Edition), 385-390. Oxford: Academic Press.

Jayasena, Dinesh D., Hyun Joo Kim, Hae In Yong, Sanghoo Park, Kijung Kim, Wonho Choe, and Cheorun Jo. 2015. "Flexible thin-layer dielectric barrier discharge plasma treatment of pork butt and beef loin: Effects on pathogen inactivation and meat-quality attributes." Food Microbiology no. 46:51-57. doi: http://dx.doi.org/10.1016/j.fm.2014.07.009.

Jiao, Yang, Juming Tang, and Shaojin Wang. 2014. "A new strategy to improve heating uniformity of low moisture foods in radio frequency treatment for pathogen control." Journal of Food Engineering no. 141:128-138. doi: http://dx.doi.org/10.1016/j.jfoodeng.2014.05.022.

Johnson, Michael. 2010. "Barriers to innovation adoption: a study of e-markets." Industrial Management \& Data Systems no. 110 (2):157-174.

Kapoor, Rahul, and Joon Mahn Lee. 2013. "Coordinating and competing in ecosystems: How organizational forms shape new technology investments." Strategic Management Journal no. 34 (3):274-296.

Kaur, Nimratbir, and AK Singh. 2015. "Ohmic Heating: Concept and Applications-A Review." Critical reviews in food science and nutrition (just-accepted):00-00.

Khan, Muhammad Ammar, Sher Ali, Muhammad Abid, Hussain Ahmad, Lixia Zhang, Ronald Keith Tume, and Guanghong Zhou. 2014. "Enhanced texture, yield and safety of a 
ready-to-eat salted duck meat product using a high pressure-heat process." Innovative Food Science \& Emerging Technologies no. 21:50-57. doi: http://dx.doi.org/10.1016/j.ifset.2013.10.008.

Knoerzer, Kai, Pablo Juliano, Peter Roupas, and Cornelis Versteeg. 2011. Innovative food processing technologies: advances in multiphysics simulation: John Wiley \& Sons.

Korachi, May, Fatma Ozen, Necdet Aslan, Lucia Vannini, Maria Elisabetta Guerzoni, Davide Gottardi, and Fatma Yesim Ekinci. 2015. "Biochemical changes to milk following treatment by a novel, cold atmospheric plasma system." International Dairy Journal no. 42:64-69. doi: http://dx.doi.org/10.1016/j.idairyj.2014.10.006.

Koutchma, T. , and L. Keener. 2015. Novel Food Safety Technologies Emerge in Food Production. Food Safety Magazine.

Koutchma, Tatiana. 2014. Food Plant Safety: UV Applications for Food and Non-food Surfaces: Elsevier.

Koutchma, Tatiana, Vladimir Popović, Valquiria Ros-Polski, and Anthony Popielarz. 2016. "Effects of ultraviolet light and high-pressure processing on quality and health-related constituents of fresh juice products." Comprehensive Reviews in Food Science and Food Safety no. 15 (5):844-867.

Kumar, Sanjeev, Sudhanshu Saxena, Jyoti Verma, and Satyendra Gautam. 2016. "Development of ambient storable meal for calamity victims and other targets employing radiation processing and evaluation of its nutritional, organoleptic, and safety parameters." LWT-Food Science and Technology no. 69:409-416.

Lee, Hanna, Jung Eun Kim, Myong-Soo Chung, and Sea C. Min. 2015. "Cold plasma treatment for the microbiological safety of cabbage, lettuce, and dried figs." Food Microbiology no. 51:74-80. doi: http://dx.doi.org/10.1016/j.fm.2015.05.004.

Lee, Seung Hyun, Won Choi, and Soojin Jun. 2016. "Conventional and Emerging Combination Technologies for Food Processing." Food Engineering Reviews:1-21. doi: 10.1007/s12393-016-9145-3.

Leonelli, Cristina, and Timothy J Mason. 2010. "Microwave and ultrasonic processing: now a realistic option for industry." Chemical Engineering and Processing: Process Intensification no. 49 (9):885-900.

Liu, Wenjie, and Tyre C Lanier. 2016. "Rapid (microwave) heating rate effects on texture, fat/water holding, and microstructure of cooked comminuted meat batters." Food Research International no. 81:108-113.

Lohani, Umesh C., and K. Muthukumarappan. 2016. "Application of the pulsed electric field to release bound phenolics in sorghum flour and apple pomace." Innovative Food Science \& Emerging Technologies no. 35:29-35. doi: http://dx.doi.org/10.1016/j.ifset.2016.03.012.

Long, Thomas B, Vincent Blok, and Ingrid Coninx. 2016. "Barriers to the adoption and diffusion of technological innovations for climate-smart agriculture in Europe: evidence from the Netherlands, France, Switzerland and Italy." Journal of Cleaner Production no. 112:9-21.

Loypimai, Patiwit, Anuchita Moongngarm, Pheeraya Chottanom, and Tanongsak Moontree. 2015. "Ohmic heating-assisted extraction of anthocyanins from black rice bran to prepare a natural food colourant." Innovative Food Science \& Emerging Technologies no. 27:102-110. doi: http://dx.doi.org/10.1016/j.ifset.2014.12.009.

Ma, Qianli, Nazimah Hamid, Indrawati Oey, Kevin Kantono, Farnaz Faridnia, Michelle Yoo, and Mustafa Farouk. 2016. "Effect of chilled and freezing pre-treatments prior to pulsed electric field processing on volatile profile and sensory attributes of cooked lamb meats." Innovative Food Science \& Emerging Technologies. 
1063

1064

1065

1066

1067

1068

1069

1070

1071

1072

1073

1074

1075

1076

1077

1078

1079

1080

1081

1082

1083

1084

1085

1086

1087

1088

1089

1090

1091

1092

1093

1094

1095

1096

1097

1098

1099

1100

1101

1102

1103

1104

1105

1106

1107

1108

1109

1110

1111

Ma, Xin, and Peter McSweeney. 2008. "Product and process innovation in the food processing industry: case study in Guangxi province." Australian Agribusiness Review no. 16 (6).

Maloney, Norman, and Michael Harrison. 2016. "Chapter 8 - Advanced Heating Technologies for Food Processing A2 - Leadley, C.E." In Innovation and Future Trends in Food Manufacturing and Supply Chain Technologies, 203-256. Woodhead Publishing.

Mao, Weijie, Yuko Oshima, Youko Yamanaka, Mika Fukuoka, and Noboru Sakai. 2011. "Mathematical simulation of liquid food pasteurization using far infrared radiation heating equipment." Journal of Food Engineering no. 107 (1):127-133. doi: http://dx.doi.org/10.1016/j.jfoodeng.2011.05.024.

Marathe, SA, R Deshpande, Arohi Khamesra, Geeta Ibrahim, and Sahayog N Jamdar. 2016. "Effect of radiation processing on nutritional, functional, sensory and antioxidant properties of red kidney beans." Radiation Physics and Chemistry no. 125:1-8.

Mason, T. J., F. Chemat, and M. Ashokkumar. 2015. "Power ultrasonics for food processing." In Power Ultrasonics, 815-843. Oxford: Woodhead Publishing.

Milliou, Chrysovalantou, and Emmanuel Petrakis. 2011. "Timing of technology adoption and product market competition." International Journal of Industrial Organization no. 29 (5):513-523.

Minjares-Fuentes, R, A Femenia, MC Garau, MG Candelas-Cadillo, S Simal, and C Rosselló. 2016. "Ultrasound-assisted extraction of hemicelluloses from grape pomace using response surface methodology." Carbohydrate Polymers no. 138:180-191.

Mishra, Radha Raman, and Apurbba Kumar Sharma. 2016. "Microwave-material interaction phenomena: Heating mechanisms, challenges and opportunities in material processing." Composites Part A: Applied Science and Manufacturing no. 81:78-97. doi: http://dx.doi.org/10.1016/j.compositesa.2015.10.035.

Misra, NN, BK Tiwari, KSMS Raghavarao, and PJ Cullen. 2011. "Nonthermal plasma inactivation of food-borne pathogens." Food Engineering Reviews no. 3 (3-4):159-170.

Mohamed, Maged EA, H Ayman, and Amer Eissa. 2012. Pulsed electric fields for food processing technology: INTECH Open Access Publisher.

Monteiro, Ricardo L., Bruno A. M. Carciofi, and João B. Laurindo. 2016. "A microwave multiflash drying process for producing crispy bananas." Journal of Food Engineering no. 178:1-11. doi: http://dx.doi.org/10.1016/j.jfoodeng.2015.12.024.

Morehouse, Kim M, and Vanee Komolprasert. 2004. "Irradiation of food and packaging: an overview." In.: ACS Publications.

Moreirinha, Catarina, Adelaide Almeida, Jorge A Saraiva, and Ivonne Delgadillo. 2016. "Highpressure processing effects on foodborne bacteria by mid-infrared spectroscopy analysis." LWT-Food Science and Technology.

Moskowitz, Howard R, Jacqueline H Beckley, and Anna VA Resurreccion. 2012. Sensory and consumer research in food product design and development: John Wiley \& Sons.

Nagaraj, Ganashree, Rakesh Singh, Yen-Con Hung, and Anand Mohan. 2015. "Effect of radiofrequency on heating characteristics of beef homogenate blends." LWT - Food Science and Technology no. 60 (1):372-376. doi: http://dx.doi.org/10.1016/j.lwt.2014.08.039.

Nasir, N Mohd, BK Lee, SS Yap, KL Thong, and SL Yap. 2016. "Cold plasma inactivation of chronic wound bacteria." Archives of biochemistry and biophysics.

Nemoto, Miriam Christi Midori Oishi, Eduardo Pinheiro Gondim de Vasconcellos, and Reed Nelson. 2010. "The adoption of new technology: conceptual model and application." Journal of Technology Management \& Innovation no. 5 (4):95-107.

Niemira, Brendan A. 2014. "Chapter 18 - Decontamination of Foods by Cold Plasma A2 - Sun, Da-Wen." In Emerging Technologies for Food Processing (Second Edition), 327-333. San Diego: Academic Press. 
1112

1113

1114

1115

1116

1117

1118

1119

1120

1121

1122

1123

1124

1125

1126

1127

1128

1129

1130

1131

1132

1133

1134

1135

1136

1137

1138

1139

1140

1141

1142

1143

1144

1145

1146

1147

1148

1149

1150

1151

1152

1153

1154

1155

1156

1157

1158

1159

1160

1161

Norton, Tomas, and Da-Wen Sun. 2008. "Recent advances in the use of high pressure as an effective processing technique in the food industry." Food and Bioprocess Technology no. 1 (1):2-34.

Novoselova, Tatiana A, Miranda PM Meuwissen, and Ruud BM Huirne. 2007. "Adoption of GM technology in livestock production chains: an integrating framework." Trends in Food Science \& Technology no. 18 (4):175-188.

Oliveira, Tiago, and Maria Fraga Martins. 2010. Information technology adoption models at firm level: review of literature. Paper read at European Conference on Information Management and Evaluation.

Olsen, Nina Veflen, Klaus G Grunert, and Anne-Mette Sonne. 2010. "Consumer acceptance of high-pressure processing and pulsed-electric field: a review." Trends in Food Science \& Technology no. 21 (9):464-472.

Olsen, Nina Veflen, Elena Menichelli, Klaus G Grunert, Anne-Mette Sonne, Elizabeth Szabo, Diána Bánáti, and Tormod Næs. 2011. "Choice probability for apple juice based on novel processing techniques: Investigating the choice relevance of mean-end-chains." Food Quality and Preference no. 22 (1):48-59.

Oms-Oliu, Gemma, Olga Martín-Belloso, and Robert Soliva-Fortuny. 2010. "Pulsed light treatments for food preservation. A review." Food and Bioprocess Technology no. 3 (1):13.

Oteiza, Juan M, Leda Giannuzzi, and Noemí Zaritzky. 2010. "Ultraviolet treatment of orange juice to inactivate E. coli O157: H7 as affected by native microflora." Food and Bioprocess Technology no. 3 (4):603-614.

Ozkoc, O. Semin, Gülüm Sumnu, and Serpil Sahin. 2014. "Recent Developments in Microwave Heating." In Emerging Technologies for Food Processing (Second Edition), edited by Sun DW, 361-383. San Diego: Academic Press.

Pan, Zhongli, Griffiths G. Atungulu, and Xuan Li. 2014. "Infrared Heating." In Emerging Technologies for Food Processing (Second Edition), edited by Da-Wen Sun, 461-474. San Diego: Academic Press.

Pan, Zhongli, Chandrasekar Venkitasamy, and Xuan Li. 2016. "Infrared Processing of Foods." In Reference Module in Food Science. Elsevier.

Pankaj, Shashi Kishor, C Bueno-Ferrer, NN Misra, V Milosavljević, CP O'Donnell, Paula Bourke, KM Keener, and PJ Cullen. 2014. "Applications of cold plasma technology in food packaging." Trends in Food Science \& Technology no. 35 (1):5-17.

Patist, Alex, and Darren Bates. 2008. "Ultrasonic innovations in the food industry: From the laboratory to commercial production." Innovative Food Science \& Emerging Technologies no. 9 (2):147-154.

Pingen, Sylvia, Nadine Sudhaus, André Becker, Carsten Krischek, and Günter Klein. 2016. "High pressure as an alternative processing step for ham production." Meat Science no. 118:22-27. doi: http://dx.doi.org/10.1016/j.meatsci.2016.03.014.

Pingret, Daniella, Anne-Sylvie Fabiano-Tixier, and Farid Chemat. 2013. "Degradation during application of ultrasound in food processing: a review." Food Control no. 31 (2):593606.

Ramaswamy, HS, M Marcotte, S Sastry, and K Abdelrahim. 2014. "Ohmic heating in food processing." Ohmic heating in food processing.

Ramaswamy, R., K. Krishnamurthy, and S. Jun. 2012. "15 - Microbial decontamination of food by infrared (IR) heating." In Microbial Decontamination in the Food Industry, 450471. Woodhead Publishing.

Rastogi, N. K. 2015. "5 - Infrared heating of foods and its combination with electron beam processing." In Electron Beam Pasteurization and Complementary Food Processing Technologies, 61-82. Woodhead Publishing. 
1162

1163

1164

1165

1166

1167

1168

1169

1170

1171

1172

1173

1174

1175

1176

1177

1178

1179

1180

1181

1182

1183

1184

1185

1186

1187

1188

1189

1190

1191

1192

1193

1194

1195

1196

1197

1198

1199

1200

1201

1202

1203

1204

1205

1206

1207

1208

1209

1210

1211
Rastogi, Navin K. 2012. "Recent trends and developments in infrared heating in food processing." Critical Reviews in Food Science and Nutrition no. 52 (9):737-760.

Rawson, A., A. Patras, B. K. Tiwari, F. Noci, T. Koutchma, and N. Brunton. 2011. "Effect of thermal and non thermal processing technologies on the bioactive content of exotic fruits and their products: Review of recent advances." Food Research International no. 44 (7):1875-1887. doi: http://dx.doi.org/10.1016/j.foodres.2011.02.053.

Rivas, Javier. 2010. "The effects of the market structure on the adoption of evolving technologies." Journal of Economic Dynamics and Control no. 34 (12):2485-2493.

Rogers, Everett M. 2010. Diffusion of innovations: Simon and Schuster.

Rollin, Fanny, Jean Kennedy, and Josephine Wills. 2011. "Consumers and new food technologies." Trends in Food Science \& Technology no. 22 (2):99-111.

Roselló-Soto, Elena, Oleksii Parniakov, Qian Deng, Ankit Patras, Mohamed Koubaa, Nabil Grimi, Nadia Boussetta, Brijesh K. Tiwari, Eugène Vorobiev, Nikolai Lebovka, and Francisco J. Barba. 2016. "Application of Non-conventional Extraction Methods: Toward a Sustainable and Green Production of Valuable Compounds from Mushrooms." Food Engineering Reviews no. 8 (2):214-234. doi: 10.1007/s 12393-0159131-1.

Saxena, Juhi, Hilal Ahmad Makroo, and Brijesh Srivastava. 2016. "Optimization of timeelectric field combination for PPO inactivation in sugarcane juice by ohmic heating and its shelf life assessment." LWT - Food Science and Technology no. 71:329-338. doi: http://dx.doi.org/10.1016/j.lwt.2016.04.015.

Schlüter, O., and A. Fröhling. 2014. "NON-THERMAL PROCESSING | Cold Plasma for Bioefficient Food Processing A2 - Batt, Carl A." In Encyclopedia of Food Microbiology (Second Edition), edited by Mary Lou Tortorello, 948-953. Oxford: Academic Press.

Scholtz, Vladimir, Jarmila Pazlarova, Hana Souskova, Josef Khun, and Jaroslav Julak. 2015. "Nonthermal plasma - a tool for decontamination and disinfection." Biotechnology Advances no. 33 (6):1108-1119.

Sevenich, R, C Rauh, and D Knorr. 2016. "A scientific and interdisciplinary approach for high pressure processing as a future toolbox for safe and high quality products: A review." Innovative Food Science \& Emerging Technologies no. 38:65-75.

Sevenich, Robert, Elke Kleinstueck, Colin Crews, Warwick Anderson, Celine Pye, Katerina Riddellova, Jaromir Hradecky, Eliska Moravcova, Kai Reineke, and Dietrich Knorr. 2014. "High-Pressure Thermal Sterilization: Food Safety and Food Quality of Baby Food Puree." Journal of food science no. 79 (2):M230-M237.

Shaheen, Mohamed S, Ahmed H El-Ghorab, Faqir M Anjum, and Khaled F El-Massry. 2012. Microwave applications in thermal food processing: INTECH Open Access Publisher.

Shakhova, Nina B., Tatiana A. Yurmazova, Tran Tuan Hoang, and Nguyen Tuan Anh. 2015. "Pulsed Electric Discharge in Active Metallic Grains for Water Purification Processes." Procedia Chemistry no. 15:292-300. doi: http://dx.doi.org/10.1016/j.proche.2015.10.047.

Siegrist, Michael. 2008. "Factors influencing public acceptance of innovative food technologies and products." Trends in Food Science \& Technology no. 19 (11):603608.

Sonne, Anne-Mette, Klaus G Grunert, Nina Veflen Olsen, Britt-Signe Granli, Erzsebet Szabo, and Diana Banati. 2012. "Consumers' perceptions of HPP and PEF food products." British Food Journal no. 114 (1):85-107.

Soria, Ana Cristina, and Mar Villamiel. 2010. "Effect of ultrasound on the technological properties and bioactivity of food: a review." Trends in Food Science \& Technology no. 21 (7):323-331.

Sun, Da-Wen. 2014. Emerging technologies for food processing: Elsevier. 
Suri, Tavneet. 2011. "Selection and comparative advantage in technology adoption." Econometrica no. 79 (1):159-209.

Tang, Juming. 2015. "Unlocking Potentials of Microwaves for Food Safety and Quality." Journal of Food Science no. 80 (8):E1776-E1793. doi: 10.1111/1750-3841.12959.

Teagasc. 2016. Food Innovation Gateways: Novel Technologies for a Competitive Food Industry. edited by Ashtown Teagasc Food Research Centre, Dublin 15, Ireland.

Toepfl, S., and V. Heinz. 2007. Pulsed Electric Field processing of foods. New Food.

Toepfl, Stefan, Claudia Siemer, Guillermo Saldaña-Navarro, and Volker Heinz. 2014. "Overview of Pulsed Electric Fields Processing for Food." In Emerging Technologies for Food Processing (Second Edition), edited by Da-Wen Sun, 93-114. San Diego: Academic Press.

Tornatzky, Louis G, Mitchell Fleischer, and Alok K Chakrabarti. 1990. Processes of technological innovation: Lexington Books.

Tribst, Alline Artigiani Lima, Bruno Ricardo de Castro Leite Júnior, Miguel Meirelles de Oliveira, and Marcelo Cristianini. 2016. "High pressure processing of cocoyam, Peruvian carrot and sweet potato: Effect on oxidative enzymes and impact in the tuber color." Innovative Food Science \& Emerging Technologies no. 34:302-309. doi: http://dx.doi.org/10.1016/j.ifset.2016.02.010.

Tsevdou, Maria S., Evangelia G. Eleftheriou, and Petros S. Taoukis. 2013. "Transglutaminase treatment of thermally and high pressure processed milk: Effects on the properties and storage stability of set yoghurt." Innovative Food Science \& Emerging Technologies no. 17:144-152. doi: http://dx.doi.org/10.1016/j.ifset.2012.11.004.

Urbain, Walter. 2012. Food irradiation: Elsevier.

Uyar, Rahmi, Tesfaye Faye Bedane, Ferruh Erdogdu, T. Koray Palazoglu, Karim W. Farag, and Francesco Marra. 2015. "Radio-frequency thawing of food products - A computational study." Journal of Food Engineering no. 146:163-171. doi: http://dx.doi.org/10.1016/j.jfoodeng.2014.08.018.

Valero, A., M. Cejudo, and R. M. García-Gimeno. 2014. "Inactivation kinetics for Salmonella Enteritidis in potato omelet using microwave heating treatments." Food Control no. 43:175-182. doi: http://dx.doi.org/10.1016/j.foodcont.2014.03.009.

Van Boekel, Martinus, Vincenzo Fogliano, Nicoletta Pellegrini, Catherine Stanton, Gabriele Scholz, Sam Lalljie, Veronika Somoza, Dietrich Knorr, Pratima Rao Jasti, and Gerhard Eisenbrand. 2010. "A review on the beneficial aspects of food processing." Molecular Nutrition \& Food Research no. 54 (9):1215-1247.

Van Der Meulen, Bernd. 2011. Private food Law: Governing food chains through contract law, self-regulation, private standards, audits and certification Schemes: Wageningen Academic Publishers.

Varghese, K. Shiby, M. C. Pandey, K. Radhakrishna, and A. S. Bawa. 2014. "Technology, applications and modelling of ohmic heating: a review." Journal of Food Science and Technology no. 51 (10):2304-2317. doi: 10.1007/s13197-012-0710-3.

Verneau, Fabio, Francesco Caracciolo, Adele Coppola, and Pasquale Lombardi. 2014. "Consumer fears and familiarity of processed food. The value of information provided by the FTNS." Appetite no. 73:140-146.

Vieites, Alvaro Gómez, and José Luis Calvo. 2011. "A study on the factors that influence innovation activities of Spanish big firms." Technology and Investment no. 2011.

Wang, Yong, Xuan Li, Gang Sun, Dong Li, and Zhongli Pan. 2014. "A comparison of dynamic mechanical properties of processing-tomato peel as affected by hot lye and infrared radiation heating for peeling." Journal of Food Engineering no. 126:27-34. doi: http://dx.doi.org/10.1016/j.jfoodeng.2013.10.032. 
Wongsa-Ngasri, Pisit, and Sudhir K. Sastry. 2016. "Tomato peeling by ohmic heating: Effects of lye-salt combinations and post-treatments on weight loss, peeling quality and firmness." Innovative Food Science \& Emerging Technologies no. 34:148-153. doi: http://dx.doi.org/10.1016/j.ifset.2016.01.013.

Yildiz-Turp, G., I. Y. Sengun, P. Kendirci, and F. Icier. 2013. "Effect of ohmic treatment on quality characteristic of meat: A review." Meat Science no. 93 (3):441-448. doi: http://dx.doi.org/10.1016/j.meatsci.2012.10.013.

Zhang, Min, Jin Tang, AS Mujumdar, and S Wang. 2006. "Trends in microwave-related drying of fruits and vegetables." Trends in Food Science \& Technology no. 17 (10):524-534.

Zheng, Ajuan, Bo Zhang, Liyang Zhou, and Shaojin Wang. 2016. "Application of radio frequency pasteurization to corn (Zea mays L.): Heating uniformity improvement and quality stability evaluation." Journal of Stored Products Research no. 68:63-72. doi: http://dx.doi.org/10.1016/j.jspr.2016.04.007.

Zhou, Liyang, and Shaojin Wang. 2016. "Verification of radio frequency heating uniformity and Sitophilus oryzae control in rough, brown, and milled rice." Journal of Stored Products Research no. 65:40-47. doi: http://dx.doi.org/10.1016/j.jspr.2015.12.003.

Zhou, Yijing, Mukund V. Karwe, and Karl R. Matthews. 2016. "Differences in inactivation of Escherichia coli O157:H7 strains in ground beef following repeated high pressure processing treatments and cold storage." Food Microbiology no. 58:7-12. doi: http://dx.doi.org/10.1016/j.fm.2016.02.010.

Zinoviadou, Kyriaki G, Charis M Galanakis, Mladen Brnčić, Nabil Grimi, Nadia Boussetta, Maria J Mota, Jorge A Saraiva, Ankit Patras, Brijesh Tiwari, and Francisco J Barba. 2015. "Fruit juice sonication: Implications on food safety and physicochemical and nutritional properties." Food Research International no. 77:743-752. 


\section{Figure captions}

1287 Fig. 1. Conveyor based modular industrial microwave systems (Photo curtesy: Thermex 1288 Thermatron, USA).

1289 Fig. 2. Industrial RF conveyor based drying system (Photo curtesy: Thermex Thermatron, 1290 USA).

1291 Fig. 3. The stages of technology adoption by the industry (Rollin, Kennedy, and Wills 2011, 1292 Novoselova, Meuwissen, and Huirne 2007).

1293 Fig. 4. Conceptual model of factors impacting adoption of novel technologies (Biagini et al. 1294 2014, Gatignon and Robertson 1989).

1295 Fig. 5. Theoretical basis of adoption of technology by consumers (Fischer et al. 2013). 


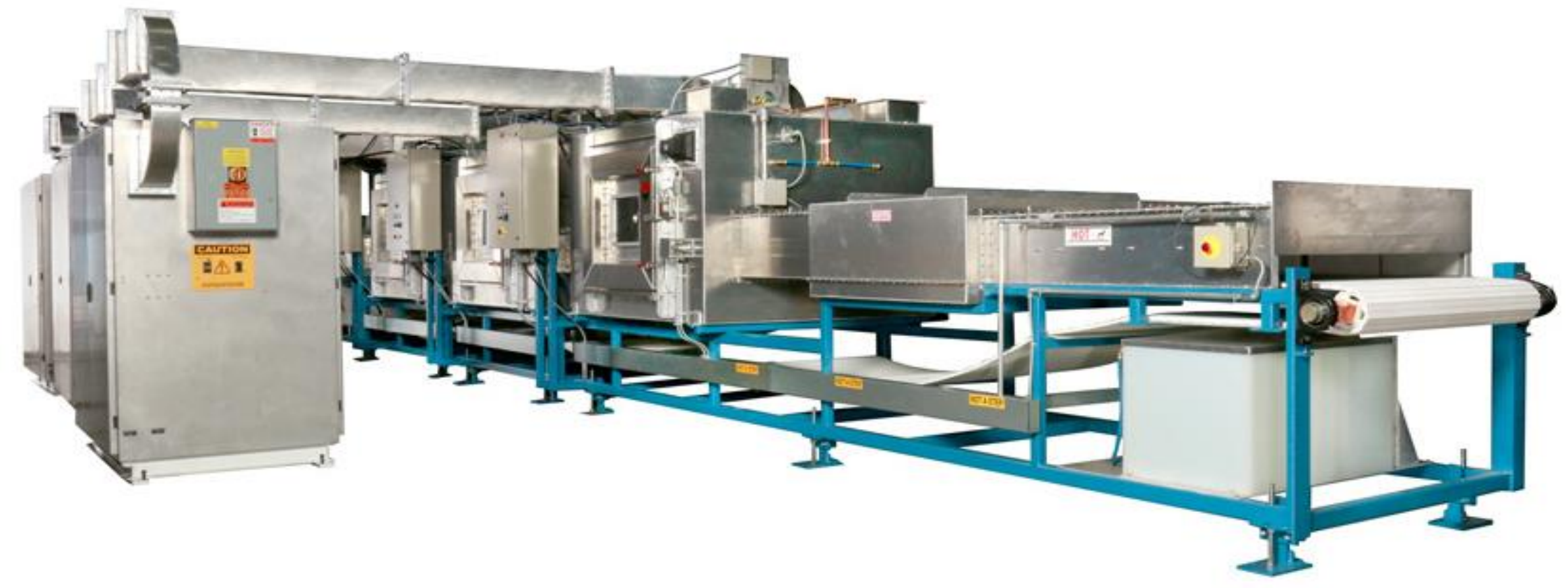

$1297 \quad$ Fig. 1. 


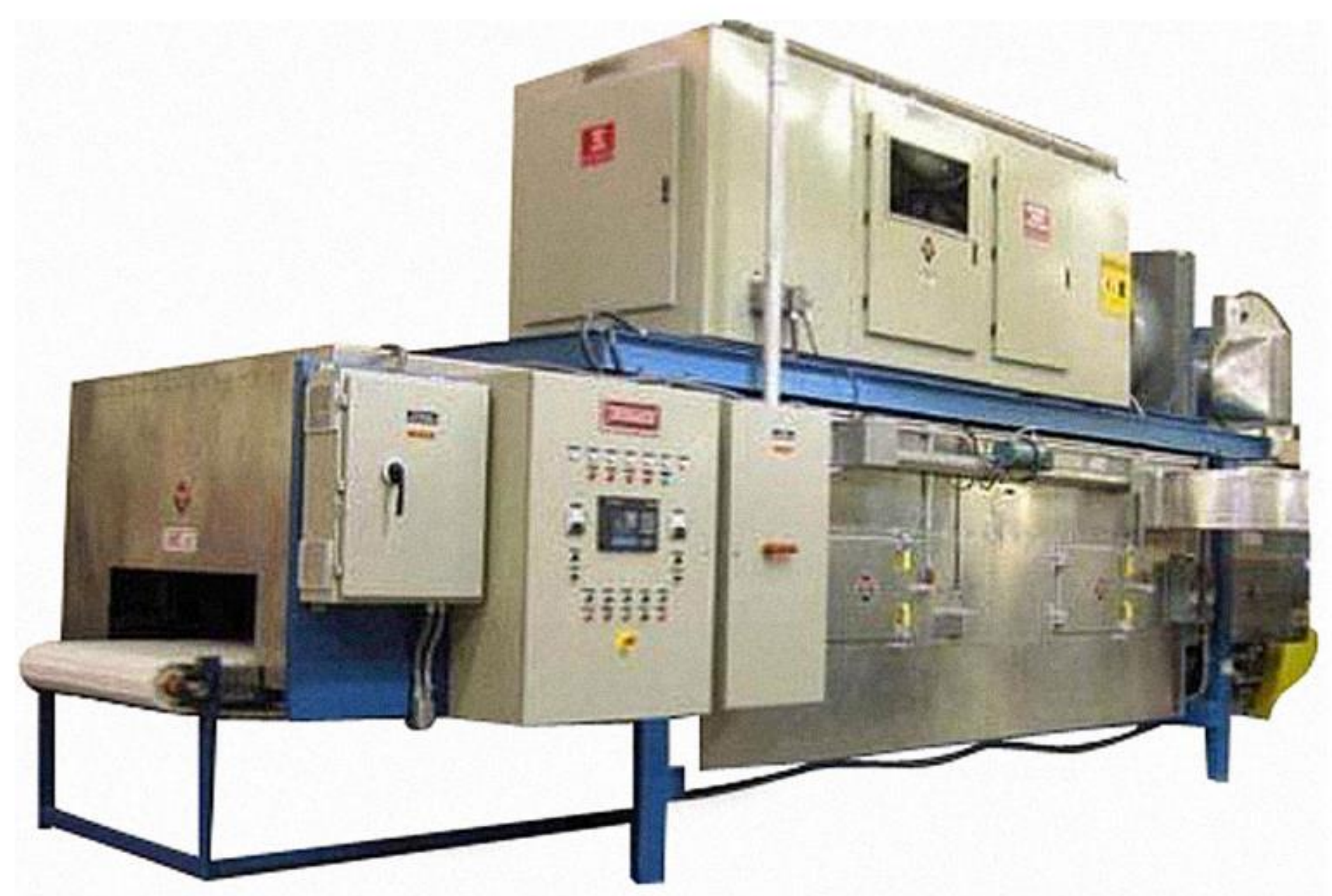

1298

$1299 \quad$ Fig. 2. 


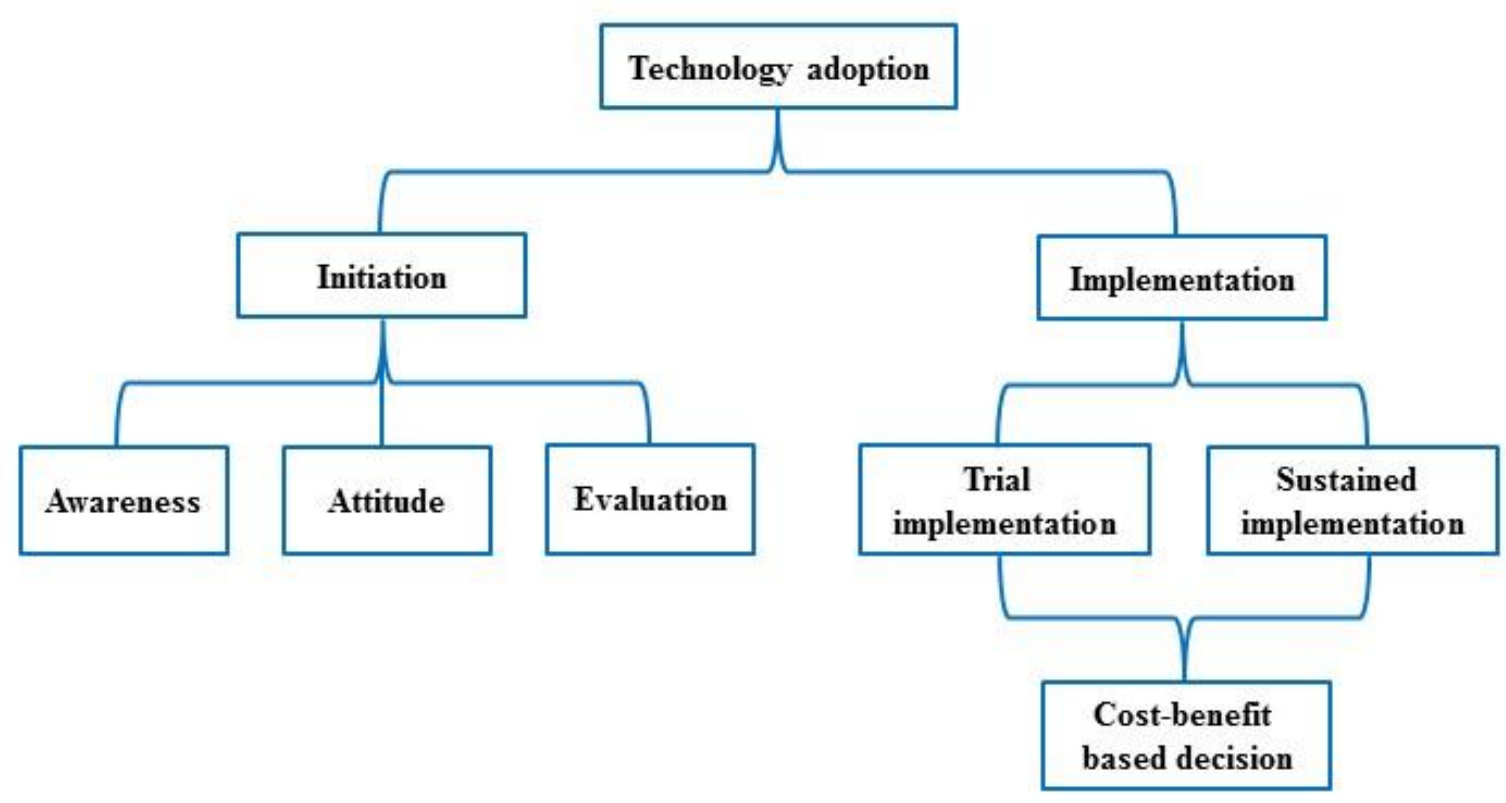

$1301 \quad$ Fig. 3. 


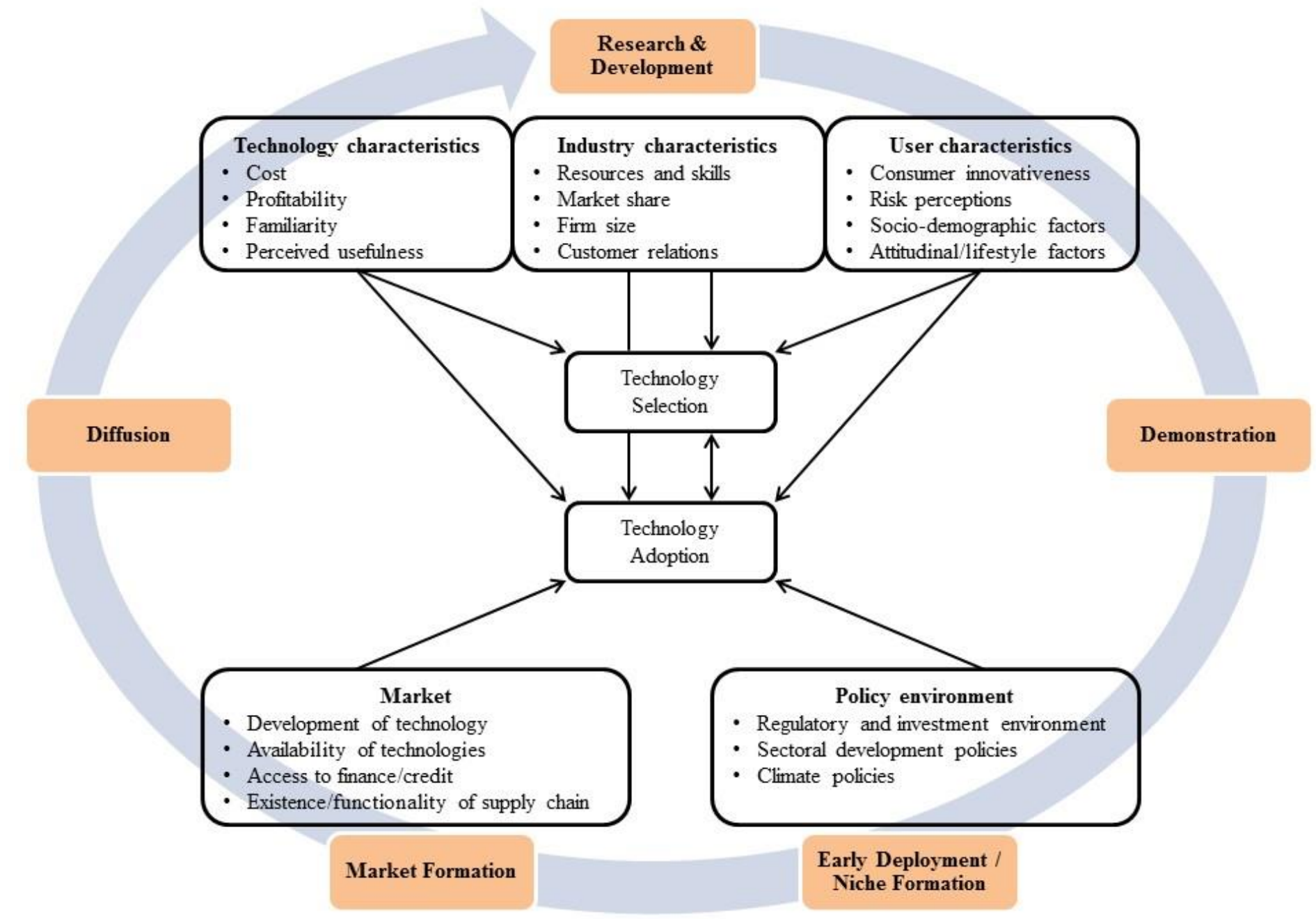

Fig. 4. 


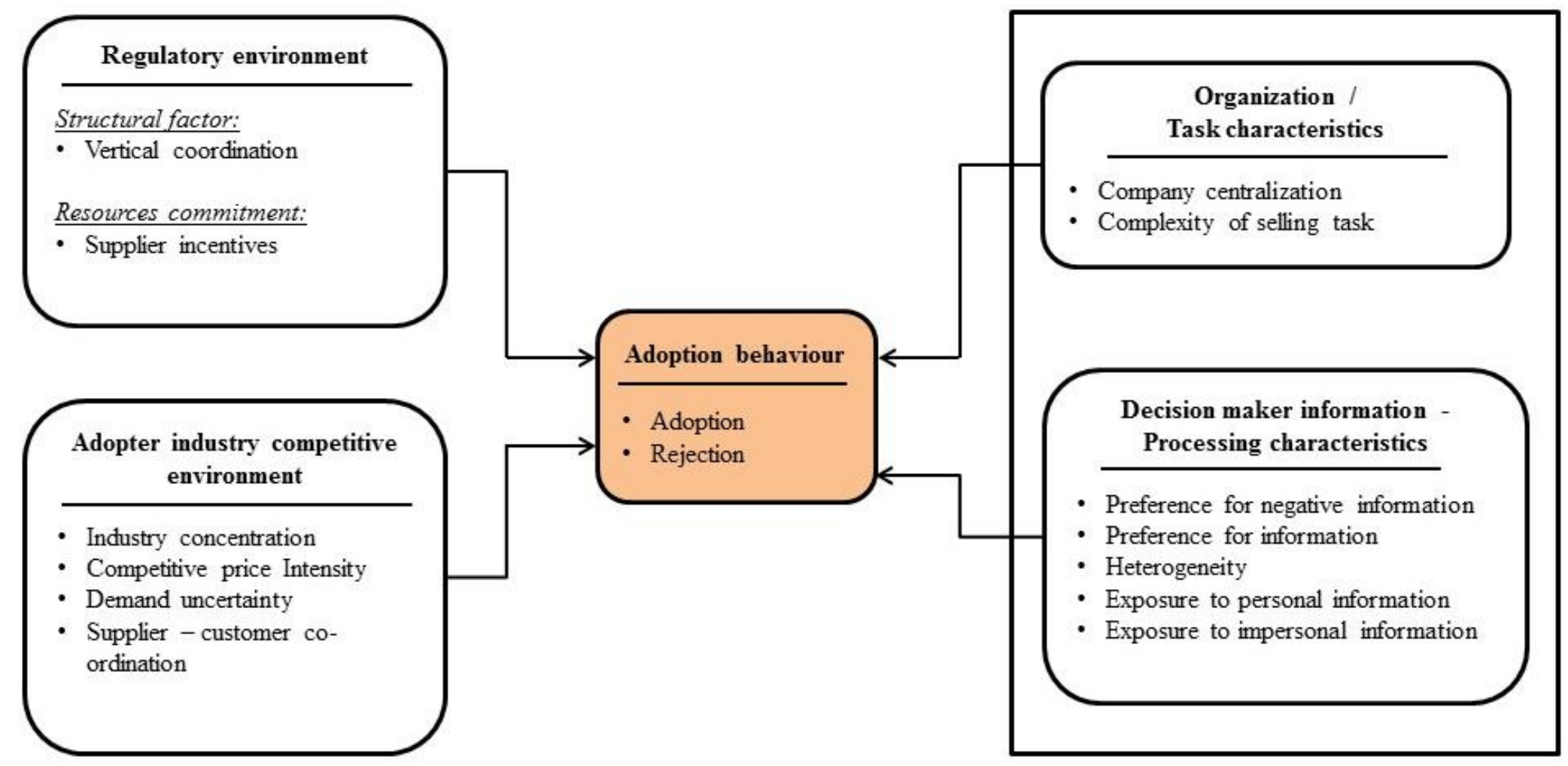

Fig. 5. 
1306 Table 1 Advantages and limitations of some novel food processing technologies and their commercial applications

\begin{tabular}{|c|c|c|c|}
\hline Process technology & Advantages & Limitations & Commercial applications \\
\hline \multicolumn{4}{|l|}{ Thermal technologies } \\
\hline $\begin{array}{l}\text { Radio } \\
\text { Heating }\end{array}$ & $\begin{array}{l}\text { - Increased throughput and reduced } \\
\text { footprint } \\
\text { - Shorter process lines with instant } \\
\text { start up } \\
\text { - Contactless heating } \\
\text { - Increased penetration power } \\
\text { - Improved moisture levelling } \\
\text { - More opportunity for new product } \\
\text { development } \\
\text { - May be used alone or combined } \\
\text { with conventional heating } \\
\text { - Sensory, nutritional and functional } \\
\text { values of food are less affected } \\
\text { - More energy efficient than surface } \\
\text { heating techniques }\end{array}$ & $\begin{array}{l}\text { - Equipment and operating cost } \\
\text { - Reduced power density } \\
\text { - Not good for fresh produce and } \\
\text { protein (Meat) } \\
\text { - Probiotic food cannot be treated }\end{array}$ & $\begin{array}{l}\text { - Vacuum drying of temperature } \\
\text { sensitive products } \\
\text { - Post baking drying of biscuits and } \\
\text { bakery products } \\
\text { - Defrosting of fish and meats } \\
\text { - Cooking of bacon and vegetable } \\
\text { blanching } \\
\text { - Tempering of frozen foods, such as } \\
\text { beef, butter blocks prior to ongoing } \\
\text { processing } \\
\text { - Energy efficient processing of nuts, } \\
\text { seeds, spices, dry foods, pet foods } \\
\text { - Broad application range including } \\
\text { food safety, agriculture, wood and } \\
\text { waste water treatment } \\
\text { - Disinfect, disinfest, and pasteurize } \\
\text { food products without chemicals } \\
\text { - Controls germination in grains and } \\
\text { seeds and enhanced storage quality }\end{array}$ \\
\hline Microwave Heating & $\begin{array}{l}\text { - Reduced carbon footprint } \\
\text { - May be used alone or combined } \\
\text { with conventional heating } \\
\text { - Heat generates within the products } \\
\text { - Reachable acceleration and time } \\
\text { savings }\end{array}$ & $\begin{array}{l}\text { - Need a high input of engineering } \\
\text { intelligence } \\
\text { - High energy costs } \\
\text { - Need a lot of knowledge or } \\
\text { experience to understand uneven } \\
\text { heating or the thermal runaway }\end{array}$ & $\begin{array}{l}\text { - Thawing and tempering meals } \\
\text { - Reheating of previously cooked or } \\
\text { prepared food } \\
\text { - Cooking, baking and pasteurizing } \\
\text { - Vacuum drying of thermo-labile } \\
\text { products }\end{array}$ \\
\hline
\end{tabular}



food products

- Puffing of snack foods, cooking of bacon and vegetable blanching

- Tempering of frozen foods

- Waste treatment

- Blanching, microwave assisted pasteurization and sterilization

\begin{tabular}{ll}
\hline Ohmic Heating & Allows the use of High Temperature \\
Short Time (HTST) and Ultrahigh \\
Temperature (UHT) techniques on \\
solids or suspended materials \\
$\bullet$ Generates heat within the product \\
- Energy efficient processing \\
- Volumetric and uniform heating \\
- Applicable equally in batch and \\
flow-through systems \\
$\bullet$ High throughput and reduced \\
process time
\end{tabular}

- More knowledge on the effects of applied electric field, current and frequency on different microorganisms and foods (at molecular and cellular level) are required

- Cold-spots

identification

and measurement during complex foods processing

- Detailed studies on modelling and heating pattern of complex foods are required

- Electroporation decreases the productivity of fermentation

- Not suitable for solid food products

- Materials to be treated should contain sufficient water and electrolytes
- Blanching, evaporation, extraction, dehydration, fermentation, sterilization, pasteurization and heating of foods to serving temperature

- Reduces the lag phase of the fermentation

- Causes a thermal and non-thermal lethal effect on the microorganisms

- Used in military or in long-duration space missions

- Most promising for aseptic processing of fluids containing particulates and fluids of high viscosity

- Appropriate for both liquid and solid particulates

- Highly effective for yeast cell destruction 


\begin{tabular}{|c|c|c|c|}
\hline Infra-Red Heating & $\begin{array}{l}\text { - Fast heating rate and shorter } \\
\text { response time } \\
\text { - Uniform drying temperature } \\
\text { - High degree of process control } \\
\text { - Possibility of selective heating } \\
\text { - Reduction in drying time } \\
\text { - Increased energy efficiency } \\
\text { - Better-quality finished products } \\
\text { - Clean working environment } \\
\text { - Can be combined with conventional } \\
\text { convective heating }\end{array}$ & $\begin{array}{l}\text { - Low penetration power } \\
\text { - Prolonged exposure of biological } \\
\text { materials may cause fracturing } \\
\text { - Modelling of infrared heat transfer } \\
\text { inside food is critical } \\
\text { - Radiation energy may be absorbed } \\
\text { at the surface of a food system due } \\
\text { to water content }\end{array}$ & $\begin{array}{l}\text { - Drying and dehydration of fruit and } \\
\text { vegetable products } \\
\text { - Drying of seaweed, vegetables, fish } \\
\text { flakes, and pasta } \\
\text { - Inactivates bacteria, spores, yeast } \\
\text { and mold in both liquid and solid } \\
\text { foods } \\
\text { - Other applications include roasting, } \\
\text { frying, broiling, heating, and } \\
\text { cooking meat and meat products, } \\
\text { soybeans, cereal grains, cocoa beans } \\
\text { and nuts. }\end{array}$ \\
\hline
\end{tabular}

\begin{tabular}{|c|c|c|c|}
\hline \multicolumn{4}{|c|}{ Non-thermal technologies } \\
\hline $\begin{array}{l}\text { High } \\
\text { Processing }\end{array}$ & $\begin{array}{l}\text { - No evidence of toxicity } \\
\text { - Colors, flavors and nutrients are } \\
\text { preserved } \\
\text { - Reduced processing times } \\
\text { - Uniformity of treatment throughout } \\
\text { food } \\
\text { - Desirable texture changes possible } \\
\text { - In-package processing possible }\end{array}$ & $\begin{array}{l}\text { - Little effect on food enzyme activity } \\
\text { - Some microbes may survive } \\
\text { - Expensive equipment } \\
\text { - Foods should have approx. } 40 \% \text { free } \\
\text { water for anti-microbial effect } \\
\text { - Limited packaging options } \\
\text { - Regulatory issues to be resolved }\end{array}$ & $\begin{array}{l}\text { - Kills vegetative bacteria (and spores } \\
\text { at higher temperatures) } \\
\text { - Pasteurization and sterilization of } \\
\text { fruits, vegetables, meats, sauces, } \\
\text { pickles, yoghurts and salad } \\
\text { dressings } \\
\text { - Potential for reduction or } \\
\text { elimination of chemical } \\
\text { preservatives } \\
\text { - Decontamination of high risk or } \\
\text { high value heat sensitive ingredients }\end{array}$ \\
\hline
\end{tabular}




\begin{tabular}{|c|c|c|c|}
\hline $\begin{array}{l}\text { Pulsed Electric Field } \\
\text { Processing }\end{array}$ & $\begin{array}{l}\text { - Colors, flavors \& nutrients are } \\
\text { preserved } \\
\text { - No evidence of toxicity } \\
\text { - Relatively short treatment time }\end{array}$ & $\begin{array}{l}\text { - No effect on enzymes and spores } \\
\text { - Difficult to use with conductive } \\
\text { materials } \\
\text { - Only suitable for liquids or particles } \\
\text { in liquids } \\
\text { - Only effective in combination with } \\
\text { heat } \\
\text { - By products of electrolysis may } \\
\text { adversely affect foods } \\
\text { - Safety concerns in local processing } \\
\text { environment } \\
\text { - Energy efficiency not yet certain } \\
\text { - Regulatory issues remain to be } \\
\text { resolved } \\
\text { - Presence of bubbles may lead to } \\
\text { non-uniform treatment } \\
\text { - Operational and safety issues }\end{array}$ & $\begin{array}{l}\text { - For liquid foods } \\
\text { - Pasteurization of fruit juices, soups, } \\
\text { liquid egg and milk } \\
\text { - Accelerated thawing } \\
\text { - Decontamination of heat sensitive } \\
\text { foods } \\
\text { - Inactivates vegetative cells }\end{array}$ \\
\hline Cold Plasma Treatment & $\begin{array}{l}\text { - Effective with temperature sensitive } \\
\text { products } \\
\text { - Reduce cross-contamination and the } \\
\text { establishment of biofilms on } \\
\text { equipment. } \\
\text { - Minimal effects on food quality and } \\
\text { appearance of the product } \\
\text { - No shadowing effect ensuring all } \\
\text { parts of a product are treated }\end{array}$ & $\begin{array}{l}\text { - No commercial instrument available } \\
\text { for disinfection of both food product } \\
\text { and packaging materials } \\
\text { - Used by various universities and } \\
\text { research organization but not by } \\
\text { industry } \\
\text { - No potential scale up to pilot plant } \\
\text { level for food industry yet } \\
\text { - Spores inactivation mechanism is } \\
\text { unknown } \\
\text { - Interaction of electronically excited } \\
\text { molecules with the food or } \\
\text { packaging materials needs to be } \\
\text { identified }\end{array}$ & $\begin{array}{l}\text { - Inactivates surface microflora and } \\
\text { spores on packaging materials/ food } \\
\text { surfaces } \\
\text { - Decontamination technology for } \\
\text { mild surface such as cut vegetables } \\
\text { and fresh meat } \\
\text { - Shelf-life extension or online } \\
\text { disinfection of processing } \\
\text { equipment } \\
\text { - Food packaging, preservation, food } \\
\text { contact surfaces and food } \\
\text { processing equipment } \\
\text { - Irregularly shaped packages such as } \\
\text { bottles can be effectively treated, }\end{array}$ \\
\hline
\end{tabular}


- Stability for large-scale commercial operations is not clear

- Modification of food packaging polymers is expected

- Regulatory issues contrary to technologies such as UV or pulsed light where shadowing occurs

\begin{tabular}{|c|c|c|c|}
\hline Ultrasound Processing & $\begin{array}{l}\text { - Reduction of process times and } \\
\text { temperatures } \\
\text { - Little adaptation required of existing } \\
\text { processing plant } \\
\text { - Increased heat transfer } \\
\text { - Batch or continuous operation } \\
\text { - Can be used alone or in combination } \\
\text { with heat and/or pressure } \\
\text { - Higher throughput, and lower } \\
\text { energy consumption } \\
\text { - Achieves a desired } 5 \text { log for food } \\
\text { borne pathogens in fruit juices }\end{array}$ & $\begin{array}{l}\text { - Complex mode of action } \\
\text { - Depth of penetration affected by } \\
\text { solids and air in the product } \\
\text { - Possible damage by free radicals } \\
\text { - Unwanted modification of food } \\
\text { structure and texture } \\
\text { - Needs to be used in combination } \\
\text { with another process (e.g. heating) } \\
\text { - Potential problems with scaling-up } \\
\text { plant } \\
\text { - Negatively modify some food } \\
\text { properties including flavor, color, or } \\
\text { nutritional value } \\
\text { - Possible modification of food } \\
\text { structure and texture }\end{array}$ & $\begin{array}{l}\text { - Effective against vegetative cells, } \\
\text { spores and enzymes } \\
\text { - Effective tool for microbial } \\
\text { inactivation } \\
\text { - Minimal effect on the ascorbic acid } \\
\text { content during processing } \\
\text { - Enhances extraction yield } \\
\text { - Fruit juices preservation }\end{array}$ \\
\hline Irrac & $\begin{array}{l}\text { - Excellent penetration into foods } \\
\text { - Reliable and energy efficient } \\
\text { - Little loss of food quality } \\
\text { - Suitable for large-scale production } \\
\text { - Improvement in flavor in some } \\
\text { foods }\end{array}$ & $\begin{array}{l}\text { - High capital cost } \\
\text { - Localized risks from radiation } \\
\text { - Poor consumer understanding } \\
\text { - Changes in flavor due to oxidation } \\
\text { - Difficult to detect } \\
\text { - Higher doses may produce } \\
\text { radiation-induced degradation } \\
\text { products }\end{array}$ & $\begin{array}{l}\text { - Suitable for sterilization } \\
\text { - Insecticidal } \\
\text { - Suitable for non-microbial } \\
\text { applications (e.g. sprout inhibition) } \\
\text { - Appropriate for fruits, vegetables, } \\
\text { herbs, spices, meat and fish } \\
\text { preservation } \\
\text { - Packaging }\end{array}$ \\
\hline
\end{tabular}




\begin{tabular}{|c|c|c|c|}
\hline & $\begin{array}{l}\text { - Minimal modification in the flavor, } \\
\text { color, nutrients, taste, and other } \\
\text { quality attributes of food } \\
\text { - Negligible or subtle losses of } \\
\text { bioactive compounds } \\
\text { - No increase in food temperature } \\
\text { during processing }\end{array}$ & - Formation of free radicals & $\begin{array}{l}\text { - Suitable for Raw, dry foods, or } \\
\text { processed food }\end{array}$ \\
\hline $\begin{array}{l}\text { UV and Pulsed Light } \\
\text { (PL) Treatment }\end{array}$ & $\begin{array}{l}\text { - No thermal effect, so quality and } \\
\text { nutrient content are retained } \\
\text { - Maintains food texture and nutrients } \\
\text { - Can be applied with other non- } \\
\text { thermal processing technologies } \\
\text { - Neither increases the temperature of } \\
\text { the product nor produces } \\
\text { undesirable organoleptic changes } \\
\text { - Unlike chemical biocides, UV does } \\
\text { not alter the chemical composition, } \\
\text { taste, odor or pH of the product and } \\
\text { leave no toxins or residues into the } \\
\text { process }\end{array}$ & $\begin{array}{l}\text { - PL-Mostly suitable for liquid foods } \\
\text { and surface of solid foods and hence } \\
\text { limiting its application } \\
\text { - PL-The mechanism by which pulsed } \\
\text { light induces cell death is yet to be } \\
\text { fully explained } \\
\text { - PL-Packaging materials for } \\
\text { irradiation should be chemically } \\
\text { stable } \\
\text { - PL- The material should be } \\
\text { transparent in order to allow the } \\
\text { light to pass into the food } \\
\text { - UV- More kinetic inactivation data } \\
\text { for pathogen and spoilage } \\
\text { microorganisms is required to } \\
\text { predict UV disinfection rates on } \\
\text { food surfaces } \\
\text { - UV-Dose response behavior of food } \\
\text { pathogens in viscous liquid foods } \\
\text { needs to be developed }\end{array}$ & $\begin{array}{l}\text { - Shelf-life extension of ready to eat } \\
\text { cooked meat products } \\
\text { - Surface decontamination of eggs } \\
\text { and chicken } \\
\text { - Alternative treatment to thermal } \\
\text { pasteurization of fresh juices } \\
\text { - Bacterial inactivation in fruit juices } \\
\text { and milk } \\
\text { - Decontamination of food processing } \\
\text { equipment } \\
\text { - Decontamination of food powders } \\
\text { - Water sterilization and wastewater } \\
\text { disinfection } \\
\text { - Decontamination of air and surfaces } \\
\text { - Mitigation of allergen from food }\end{array}$ \\
\hline
\end{tabular}

